\title{
STRATEGIES FOR A TRANSITION FROM FOSSIL TO NUCLEAR FUELS
}

Wolf Häfele

Alan S. Manne

June 1974

Research Reports are publications reporting on the work of the author. Any views or conclusions are those of the author, and do not necessarily reflect those of IIASA. 
Wolf Häfele and Alan S. Manne*

1. Primary Energy Sources--The Choice Between Lesser Evils

For large-scale supplies of primary energy over the next 30-50 years, no known sources are likely to be clean, safe and low cost. Fusion, solar and geothermal may turn out to be clean and/or safe, but no one can be confident that these energy sources will soon be low cost. ${ }^{1}$ Indeed, there are doubts whether fusion will even be technically feasible--let alone economically competitive.

In the absence of other technologies, the industrialized countries have hitherto relied mainly upon fossil fuels. There are difficulties with each of these fuels. Oil and gas resources are, to a large extent, located in politically unstable areas. Coal and shale are available in large quantities, but--in the absence of in situ extraction methods-will continue to be dirty and expensive. For these reasons, the industrialized countries are beginning to shift toward nuclear fuels--even though this leads to safety problems of

*The authors are indebted to Lilo Roggenland for her patience and accuracy in typing this paper. Many thanks also go to Leo Schrattenholzer for his assistance with the calculations reported here. Throughout, helpful suggestions have been received from David Bell, George Dantzig, Tjalling

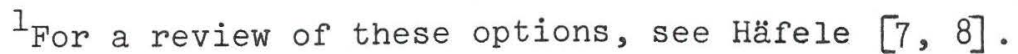


an unprecedented nature. The choice is one between lesser evils--billions of tons of soot ${ }^{2}$ or thousands of tons of plutonium. In either case, meticulous materials handing is required.

These unpleasant choices cannot be avoided by turning off a few lights, or by exhortations to travel less, or by harnessing wind and garbage power. For large-scale energy supplies, there are no near-term alternatives to fossil and nuclear fuels. To study the major options over the next 30-50 years, we shall calculate what is feasible within each of several hypothetical "model societies"--countries of the scale and level of technology of the U.S., Japan and Western Europe. It will be supposed that in one way or another these countries will make deliberate efforts to reduce the rate of growth of their demands for energy .

In this paper, we shall study the possibilities of a transition away from today's situation where virtually all demands for primary energy are met by fossil fuels. If this transition is to be based upon nuclear fission, the following aspects must be explored:

- the limited reserves of oil and gas

- the limited reserves of low cost uranium

- the limited industrial capacity for construction of nuclear reactors

\footnotetext{
${ }^{2}$ See the report on shale oil entitled "700,000,000,000
} Barrels of Soot," Sierra Club Bulletin, Sumner and Johnson
- the limited financial resources available to the energy supplying sector, here reflected by a $10 \%$ annual discount rate.

The deployment of the fast breeder reactor will open up a qualitatively new dimension of fuel supplies. This technology makes it possible to extract roughly 100 times more energy from a given amount of natural uranium than can be obtained through other reactors available today. This makes it economically feasible to exploit deposits with a very low uranium content, and virtually eliminates natural resource constraints upon energy supplies. In our view, any transition from fossil to nuclear fuels will therefore lead to a breeder power economy.

We shall analyze the timing of this transition and the interplay between several elements--limited fuel resources, limited financial means, and the needs for nuclear reactor construction. Large investment decisions are involved, and it is hoped that this study will throw some light upon those decisions. For instance: Will it make more sense to invest in nuclear engineering infrastructure or in the opening of new coal mines or in tertiary oil recovery methods? Within limits, we hope that this study will also contribute to the economic assessment of new technologies--reactor types and hydrogen production devices.

Our models of the transition from fossil to nuclear fuels are quite different from the reactor strategy calculations of 
the 1960's. Then only the electric power sector was considered, and attention was focused upon the dynamics of the competition between various reactor types. Such competition is not the point of this paper. In fact, many nuclear reactor types (e.g. the heavy water reactor, the molten salt breeder, and possible configurations containing them) must be considered if the transition problems are to be studied exhaustively. Here we want to study only one obvious reactor configuration without going into details on the fuel cycle.

In addition to the interplay between natural resource scarcities and economic costs, there are other important aspects of the transition to nuclear energy: reactor safety, the handing of a large-scale fuel cycle, environmental and ecological effects--to mention but a few. The present paper does not deal with these aspects, for they are being studied in parallel at IIASA $^{3}$ and elsewhere. It seems premature to combine everything in a single all-embracing systems analysis.

\section{Secondary Forms of Energy}

If nuclear fuels are to provide more than a small fraction of the primary energy supplies, it will not be possible to rely upon electricity alone as the secondary energy carrier. Electricity is an expensive source of energy for transport and for heat. In the industrialized countries today, it is

${ }^{3}$ See the forthcoming study by $\mathrm{R}$. Avenhaus, W. Häfele and P. McGrath. typical for the primary energy inputs into electricity to constitute only $25 \%$ of the total primary energy. The balance is carried to the user principally in the form of oil and gas. To move away from fossil fuels, it will therefore become necessary to learn how to manufacture synthetics from nuclear energy .

Several fuel synthesis processes are possible. Perhaps the simplest route--and smoothest transition--would be through "open cycle" endothermic processes, utilizing nuclear heat to replace a part but not all of the inputs of coal or other fossil fuels. The energy carrier might then be hydrogen, methane, or methanol (see the coal gasification processes shown at the top of Table I). Each component of this technology is well-known today, but no production plant has yet been built.

A second option (ADAM and EVA in Table 1 ) would require some engineering development, but no fundamental research. Chemical reaction products would flow in one pipeline from the endothermic unit (EVA). The reaction would be reversed at the exothermic end (ADAM). Heat would be released there, and the reaction products would flow back to EVA in a parallel pipeline. The net effect is to transmit nuclear process heat over a longer distance than would be economical with, say, steam. Note that ADAM and EVA would be a closed-cycle system, and would not require continual inputs of coal or other fossil fuels. Moreover, since no combustion products are released, there could be large potential environmental benefits. 
Table 1. Alternative routes to fuel synthesis through nuclear process heat.

\section{a. Coal gasification:}

$$
\begin{aligned}
\text { heat }+\mathrm{C}+\mathrm{H}_{2} \mathrm{O} \longrightarrow \mathrm{CO}+\mathrm{H}_{2} & \text { (hydrogen) } \\
\mathrm{C}+2 \mathrm{H}_{2} \longrightarrow \mathrm{CH}_{4}+\text { heat } & \text { (methane) } \\
\mathrm{CO}+2 \mathrm{H}_{2} \longrightarrow \mathrm{CH}_{3} \mathrm{OH}+\text { heat } & \text { (methanol) }
\end{aligned}
$$

b. ADAM and $\mathrm{EVA}^{*}$ :

$$
\begin{array}{r}
\text { heat }+\mathrm{CH}_{4}+\mathrm{H}_{2} \mathrm{O} \longrightarrow \mathrm{CO}+3 \mathrm{H}_{2} \quad \text { (EVA - endothermic) } \\
\mathrm{CO}+3 \mathrm{H}_{2} \longrightarrow \mathrm{CH}_{4}+\mathrm{H}_{2} \mathrm{O}+\text { heat (ADAM - exothermic) }
\end{array}
$$

\section{c. Water splitting:}

$$
\begin{array}{lll}
\text { electricity }+2 \mathrm{H}_{2} \mathrm{O} \longrightarrow 2 \mathrm{H}_{2}+\mathrm{O}_{2} & \text { (electrolysis) } \\
\text { heat } & +2 \mathrm{H}_{2} \mathrm{O} \longrightarrow 2 \mathrm{H}_{2}+\mathrm{O}_{2} & \begin{array}{l}
\text { (thermochemical } \\
\text { decomposition** }
\end{array}
\end{array}
$$

Notes:

* Source: informal communication from R. Schulten and his associates at Kernforschungsanlage Jülich, Federal Republic of Germany.

**For alternative routes to thermochemical water splitting, see Marchetti [12].
In this paper, we shall concentrate upon a longer-range technological option--water splitting to produce hydrogen. Like ADAM and EVA, water splitting would be a closed-cycle system, requiring no inputs of fossil fuels. In addition, it would have the advantage that the utilization device need not be stationary. Hydrogen would be particularly useful as an airplane fuel with a high heating value per unit weight. As a fuel for automobiles or as a reducing agent for iron production, hydrogen would be virtually non-polluting.

As shown on the bottom lines of Table 1, there are two principal routes to hydrogen:

i) electrolysis, a mature but expensive technology, and

ii) thermochemical water splitting, an unproved but promising process.

In the first case, nuclear process heat would first be converted to electric energy (at, say, 40\% thermal efficiency in a fast breeder reactor), and then to hydrogen (at, say, $80 \%$ efficiency) in an electrolyzer. The overall thermal efficiency from electrolysis would then be $32 \%^{4}--$ appreciably lower than the $50 \%$ efficiency that may be possible with thermochemical processes. Roughly speaking, the relative costs of these two water splitting routes will be inversely

4 Off-peak electrolysis might play an important catalytic role in initiating a hydrogen economy, but it could have only a small impact upon the overall supplies of energy. Suppose, $25 \%$ of total primary energy inputs, and that $40 \%$ of the electricity is available for off-peak electrolysis. Then, with a $32 \%$ overall thermal efficiency from electrolysis, this source would provide only $(.25)(.40)(.32)=3.2 \%$ of total primary energy. 
proportional to their thermal efficiencies, for in both cases they would use similar inputs: nuclear fuels, capital equipment, and water.

Thermochemical decomposition would require a high temperature source of process heat--an HTR (high temperature reactor). This is a proved type of nuclear reactor, but is the only component of the water splitting technology that is already in existence. It would require a systematic chemical engineering research effort to evaluate the hundreds of thermochemical cycles that are theoretically feasible. With some luck--plus adequate funding--this effort could lead to pilot plant in the early 1980's and to a demonstration plant in the late 1980's. One of the principal aims of our paper is to calculate the economic incentive to develop this technology. The more distant are the benefits and the higher the discount rate, the lower will be this incentive.

\section{The Reactor Configuration}

Figure 1 describes the reactor configuration that is basic to our model ${ }^{5}$. The central component is the fast breeder reactor $(\mathrm{FBR})^{6}$, for this is needed in order to

5 Based upon an earlier paper by Häfele and Schikorr [97.

6 For reactor data on the base case FBR, see Appendix A Table A-1. This reactor is one of good but not unusually high breeding gain. The usual oxide fueled ( $\mathrm{PuO}_{2} / \mathrm{NO}_{2}$ ) FBR could reach this performance if a special design effort were made core radal onk FBR demonstration plants (Phénix in France, PFR in the UK, BN 350 in the USSR and SNR 300 in Germany/Belgium/Netherlands) are primarily designed for low fuel cycle costs under today's conditions of high plutonium fuel fabrication costs. These are not necessarily representative of the situation in later decades.

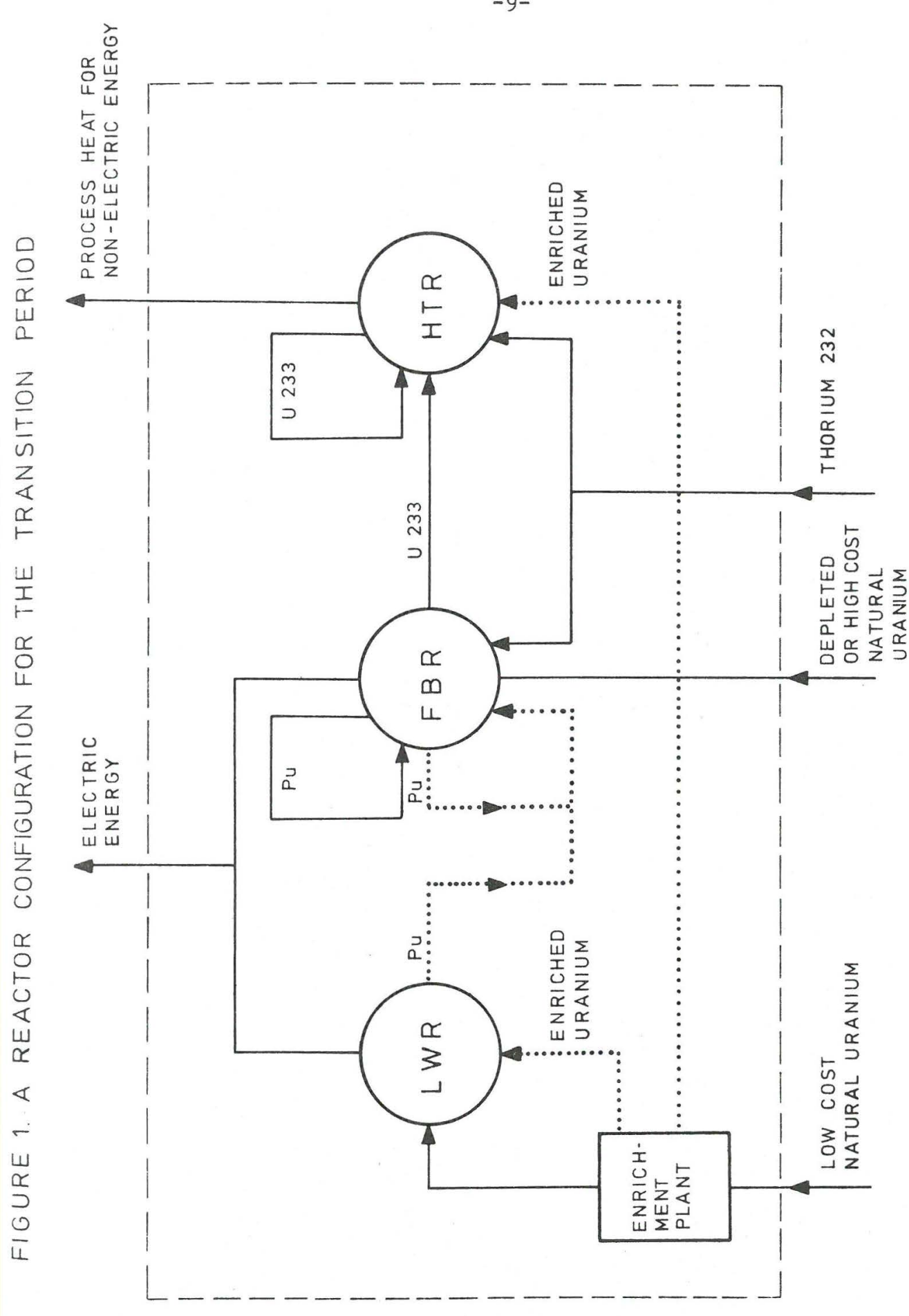


overcome the eventual scarcity of low-cost natural uranium. The other key element is the high temperature reactor (HTR). This would supply process heat for the production of nonelectric secondary energy, e.g. In the form of hydrogen.

-The FBR is not only an electricity producer, but also a "nuclear fuel factory." 7 Its breeding gain can generate plutonium ( $\mathrm{Pu}$ ) to start up new FBR capacity (initial inventories for critical masses). The breeding gain may also be employed to convert Thorium 232 into Uranium 233 to supply the annual refueling requirements of the HTR. ${ }^{8}$ In this way, the FBR's and HTR's together could supply all demands for electricity and non-electrical energy. The only natural resource requirements would then be thorium and depleted or high cost natural uranium.

During the period of transition to this configuration, light water reactors (LWR's) will also be needed--even though it is expensive to supply their annual inputs of enriched uranium. The LWR is the most common type of nuclear plant under construction today, and it bridges the time gap until FBR's become commercially available. Meanwhile, the LWR plutonium output can be stockpiled to provide the first cores that will eventually be needed in FBR's. Here we shall suppose that none of this plutonium is recycled, and that it is all stockpiled. (Recycling has already been widely studied, and it would introduce no qualitatively new features.)

${ }^{7}$ See Fortescue [6].

8 This implies, for instance, radial blankets of thorium instead of $\mathrm{U} 238$ in the FBR.
For a summary view of the nuclear technologies included in our programming model, see Figure 2. This block diagram describes the inputs and outputs of each individual process. The LWR, for example, is shown as requiring annual inputs of NU (natural uranium) and SWU (separative work units in enrichment plants). The annual outputs are abbreviated ELEC (electric energy) and NELE (non-electric energy). The annually recurring inputs and outputs for process $i$ are proportional to the installed power capacity, $\mathrm{PC}_{i}^{t}$. These levels change over time as new technologies become available. one simplification should be made explicit. According to our model, old plants remain in operation at their full capacity level until they are retired at the end of their 30-year service lives. We do not deal with the problem of the load-duration curve, nor with plants shifting over time from base load to peaking service. These considerations are important for electricity producing enterprises, but probably not at the level of aggregation adopted here.

To add to the capacities available in period $t$, positive intensities must be assigned to the investment activity variables $\mathrm{DP}_{i}^{t}$. These investments require initial inventories of fissile materials: NU and SWU for the LWR's; PLUT, Th232 and $\mathrm{U} 238$ for the FBR's, etc.

According to Figure 2, the FBR's breeding gain (abbreviated BRGN) may be allocated to the production of plutonium, an activity abbreviated FBPL. Alternatively, 
 Initial inventories of Annual flows per unit of
fissile materials re- quired for capacity in-
creases (variables $\mathrm{DP}_{i}^{t}$ ) (variables $\mathrm{PC}_{j}^{t}$ )
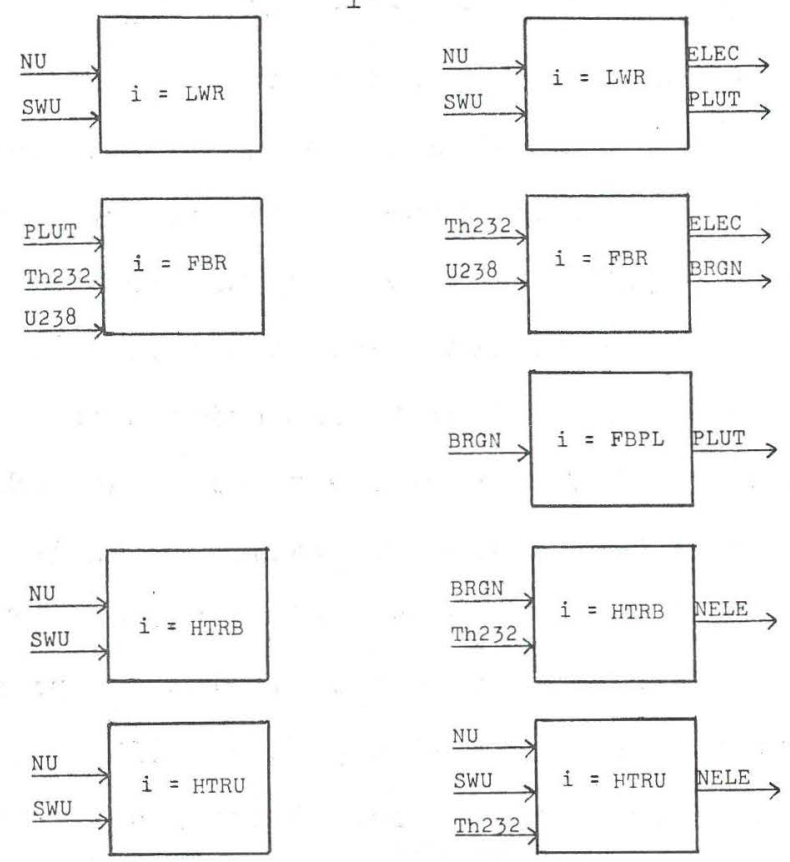

Key :

NU natural uranium (99.3\% U238; .7\% U235)

SWU separative work required for enrichment of natural uranium

BRGN breeding gain (expressed as reactor system coupling factor) ergy (base load)

- holectric energy (hydrogen or other synthetic fuels)

LWR light water reactor

FBPL fast breeder reactor - breeding gain employed for plutonium production to provide initial inventories for additional FBR'

HTRB high temperature reactor plus thermochemical plant HTRU for water splitting - fueled by 233 breeding Note:

The inputs of thorium (Th232) and of depleted uranium (U238) do not appear explicitly in the programming matrix, but are able to suppose that both these items are available in virtual-

ly unlimited quantities throughout the planning horizon. the breeding gain may be used to convert Thorium 232 into HTR fuel (see the activity labeled HTRB). Through coupling the FBR and the HTR, the net effect is to produce both electric and non-electric energy without the need for costly enrichment or natural uranium.

Even if the high temperature reactors are not coupled to the FBR, they may still be employed to produce synthetic fuels through thermochemical processes. This option is shown at the bottom of Figure 2 as the activity HTRU (high temperature reactors fueled by enriched uranium). Note that this requires inputs of natural uranium plus enrichment, but that it avoids the need for breeding gain. Hence it provides a backstop in case of initial delays with the FBR program and also--over the long-term--in case of insufficient breeding gain. The HTRU activity is excluded from our base case, but is included in a sensitivity analysis.

For a static comparison of the costs of these nuclear processes versus those for conventional fossil fuels, see Table 2. Assuming a 10\% annual discount rate and a 30-year service life, this table provides a direct ranking of the alternatives for producing the two forms of secondary energy, ELEC and NELE. It can be seen, for example, that electrolytic hydrogen is over 60\% more costly than oil (at $\$ 10$ barrel ${ }^{9}$ ) or than hydrogen produced by HTR's.

${ }^{9}$ We do not distinguish between white and black petroleum products nor between natural gas, synthetic crudes, etc. These distinctions are important for petroleum refiners, but not for this model of the energy sector as a whole. Refining margins are of the order of $\$ 1-2$ per barrel, and are small in relation to crude prices of $\$ 7-10$. 
Table 2. Static comparison of costs.

(1974 prices)

\begin{tabular}{|c|c|c|}
\hline & Plant type & $\begin{array}{l}\text { Annual cost per KW } \\
\text { thermal of primary } \\
\text { energy (expressed } \\
\text { in LWR or PETG } \\
\text { equivalents)* }\end{array}$ \\
\hline $\begin{array}{l}\text { ELEC, } \\
\text { electric } \\
\text { energy }\end{array}$ & $\begin{array}{l}\text { COAL (coal-fired) } \\
\text { LWR (light water reactors) } \\
\text { FBR (fast breeder reactors) }\end{array}$ & $\begin{array}{l}\$ 46 \\
32-36 \quad \text { (depending on } \\
31\end{array}$ \\
\hline $\begin{array}{l}\text { NELE, } \\
\text { non- } \\
\text { electric } \\
\text { energy }\end{array}$ & $\begin{array}{l}\text { ELHY (electrolytic hydrogen) } \\
\text { PETG (petroleum, gas, etc.) } \\
\text { HTRB (high temperature } \\
\text { reactor for thermo- } \\
\text { chemical water splitting) }\end{array}$ & $\begin{array}{r}\$ 84 \\
50 \\
47\end{array}$ \\
\hline
\end{tabular}

Notes:

Discount rate (before taxes): 10\% per year; 30-year service

life. These calculations neglect costs and credits for

plutonium and U233.

Costs of fossil fuels:

PETG: \$ $1.667 / \mathrm{million}$ BTU, or $\$ 10 / \mathrm{barre}$

COAL: $\$ 1.000 /$ million BTU

Note:

*A thermal kilowatt is a measure of primary energy input. To compare the costs per unit of useful energy output, it is

necessary to allow for differences in thermal efficiency between processes. In producing electrical energy, for example, the thermal efficiencles of the $33 / 40 \quad(=.833)$ is into the into LWR equivalent units. It is for this same reason that 1.2 (the reciprocal of this factor) will appear in the programming submatrix (Table 4) as the entry in the column $\mathrm{PC}_{\mathrm{FBR}}^{\mathrm{t}}$ and row $\mathrm{DM}_{\mathrm{ELEC}}^{\mathrm{t}}$.

A similar line of reasoning is employed to define the PETG equivalence of hydrogen processes. See Appendices $A$ and $B$,

particularly the co
Table 2 is easy to calculate from the basic data on capital and operating costs. It requires no programming model or dynamic simulator. At the same time, it reveals nothing about the timing or the costs of alternative strategies for a transition from an initial position of virtually total dependence upon fossil fuels. There is a further drawback in this static comparison. It is supposed that plutonium and breeding gain are so abundant that we may neglect all costs and credits for these items. It is to avoid these over-simplifications that we now turn to a programming model.

\section{A Programming Model for Reactor Strategies}

This linear programming model is intended to describe the dynamics of several "model societies." None of these calculations refer to any one country, for the aim is to understand only the basic features of the transition from fossil to nuclear fuels. It is easy enough to modify our parameters so as to allow for the demand and cost data of any specific nation.

At each point of time over a 75-year planning horizon, the fossil and nuclear energy supply activities are to be chosen so as to meet the final demands at minimum discounted ${ }^{10}$

10 Throughout, we have employed a 10\% annual discount rate, even though this may be higher than the marginal productivity of capital in most industrialized countries. A $10 \%$ rate leads the distant future. For ent value for benefits accruing in years hence, the present value is less than $\$ 6$.

It seemed preferable to adopt the $10 \%$ rate rather than to discount rate, there would be an this subject. At any lowe for substituting nuclear in place of fossil fuels. 
costs--subject to a series of technological and behavioral constraints. The final demands are for electric and nonelectric energy. For simplicity in most of the calculations (model societies 1 and 2), these demands grow at exogenous trend rates over time, or eventually remain constant. For model society 3, the demands depend upon the price of energy-as well as upon time trends related to aggregate income. In this case, we maximize the discounted utility of consumption less the costs. Throughout, the identical coefficients are employed for the costs and technology of energy supplies.

The constraints of the programming model are summarized in Table 3. In addition to the final demands, there are material balances on the supplies and demands for the intermediate items (separation work and breeding gain). There are constraints upon the cumulative amounts extracted of PETG (petroleum and gas) and of NULC (low-cost natural uranium available at $\$ 15$ per pound). There are other constraints to ensure the nonnegativity of the plutonium stockpile at each point of time. Finally, there are equations to count the cumulative consumption of coal, but not to impose any specific upper limit upon this resource.

The 75-year planning horizon is subdivided into 25 intervals, each three years in length. Within each of these representative periods, it is supposed a)that new capacity of type $i$ is added at an endogenously determined annual rate $\left.\mathrm{DP}_{i}^{t}, \mathrm{~b}\right)$ that capacity is retired after 30 years of service,
Table 3. Constraints of programming model.

$\mathrm{DM}_{j}^{t} \quad$ final demands $(j=E L E C, N E L E)$

$D_{j}^{t}$ demands for intermediate items ( $j=S W U, B R G N$ )

$\mathrm{SM}_{j}^{t}$ cumulative sums, fuel resources ( $j=$ COAL, PETG, NU, PLUT)

$\mathrm{CP}_{i}^{t}$ capacities, energy sector ( $i=$ COAL, $\ldots$, ELHY $)$

Upper bounds on reactor construction rates $\mathrm{DP}_{i}^{t}$ ( $i=L W R, F B R$, HTRB, HTRU)

Upper bounds on cumulative resource extraction CS $S_{i}^{t}$ ( $i$ = PETG, NULC)

Time index $t=0,3,6, \ldots, 75$

Calendar year $=1970,1973,1976, \ldots, 2045$

(For further details, see Appendices $A$ and $B$. ) 
and c) that it is operated at a constant rate throughout the 30-year service life. The length of the service life is an important parameter, for it limits the rate at which new technologies may be introduced in place of old ones. The slower the growth in demand, the more important become the opportunities for replacement investment. (See the equations $\mathrm{CP}_{i}^{t}$, Appendix A.)

With three years per time period, it is possible to make a fairly realistic allowance for lags in the nuclear fuel processing cycle. In the programming submatrix of Table 4 see, for example, the supplies and demands associated with the material balance row $\mathrm{SM}_{\mathrm{NU}}^{\mathrm{t}}$. According to that row, natural uranium ore is required in period $t$ for current refueling by the LWR and HTRU activities. Additional amounts are required for setting up new capacities three years later (activities $D P_{i}^{t+3}$ for $i=L W R$, HTRB, and HTRU). Through the reprocessing of spent fuel, uranium ore and separative work are, in effect, released by the retirement of these capacities after a service life of 30 years (activities $\mathrm{DP}_{i}^{t-30}$ ). Note also that the low-cost supplies available in period $t$ may be supplemented by the activity $\mathrm{PC}_{\mathrm{NUHC}}^{\mathrm{t}}$ for providing high-cost ore (at $\$ 50$ per pound). Similar interpretations may be made for each of the other rows in the programming submatrix. ${ }^{11}$

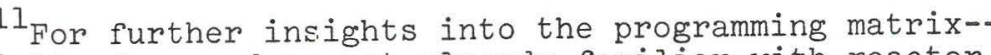
especially for reader strategy calculations--see Appendix C.

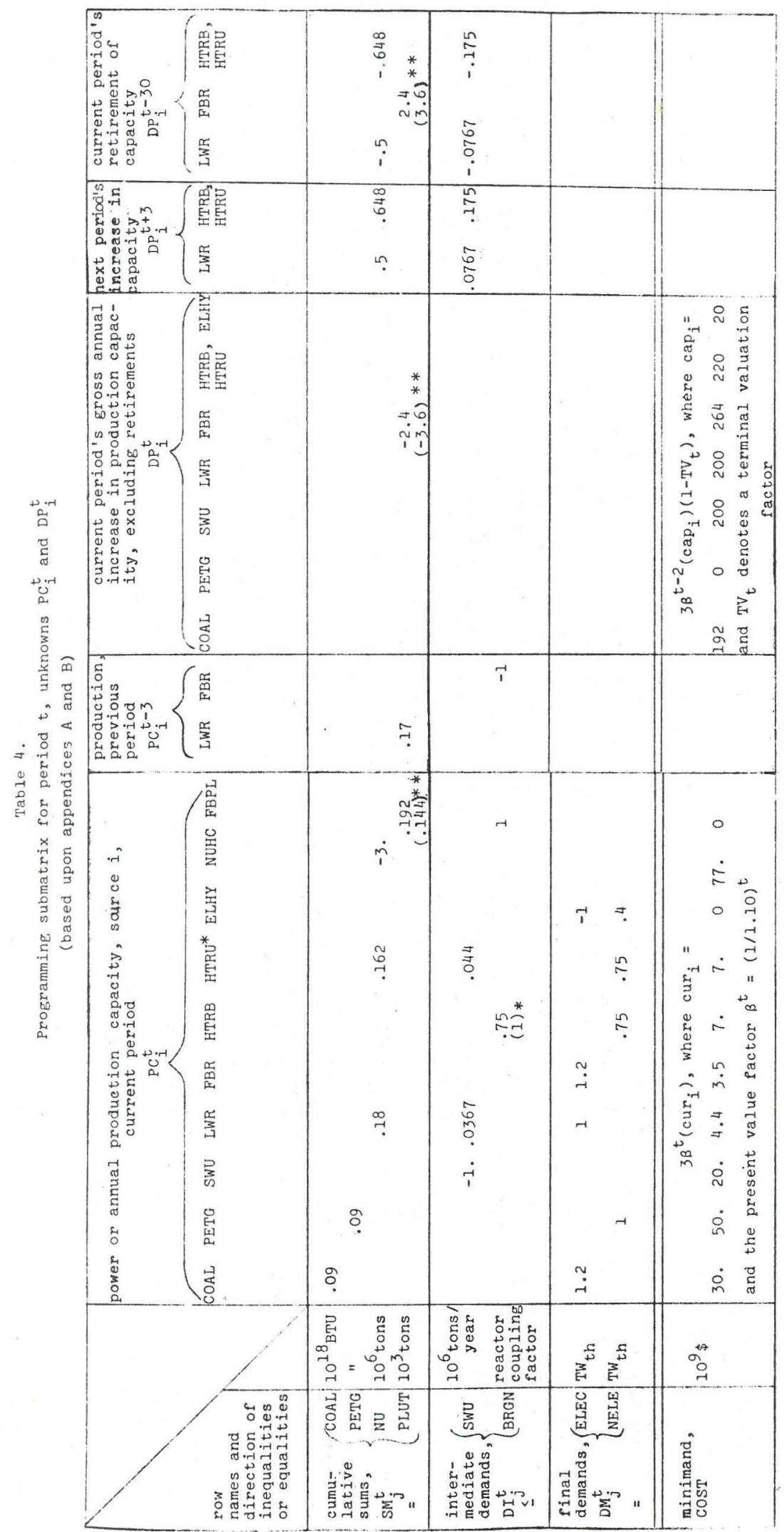


Table 4 contains 8 rows for each time period. Not shown explicitly are the 8 capacity restrictions $\mathrm{CP}_{i}^{t}$. Altogether then, with 25 periods and 16 restrictions per period, there are 400 constraint rows--not counting upper bounds on individual unknowns and not counting year 0 .

Upper bounds are specified for the reactor construction rate variables $\mathrm{DP}_{i}^{t}$ (see Table 5). These bounds are to be viewed as behavioral constraints on the rate of diffusion of new technologies. For example, when the LWR first became available, not all new electricity plants adopted this process. Similarly, when FBR's first become available, they will not be adopted by all new plants. Efforts are still required in order to demonstrate breeder safety, and thereby bring about public acceptance. Our upper bounds are rather arbitrary, but it would have been even more arbitrary to ignore the diffusion phenomenon. The numerical values in the LWR column were chosen so that the cumulative capacity installed through 1985 would not exceed $300 \mathrm{GW}$ electrical. ${ }^{12}$ For the other processes, the bounds were chosen so as to avoid sharp subsequent down-turns in construction rates.

\section{Final Demand Projections}

For each of the model societies, it will be supposed that the initial conditions are identical: a population of

12 According to WASH-1139(72), the 1985 U.S. nuclear power capacity will "most likely" be 280 , but could range from a Commission $[2, \mathrm{p} .3]$ ).
Table 5. Upper bounds on reactor construction rates $D P_{i}^{t}$.

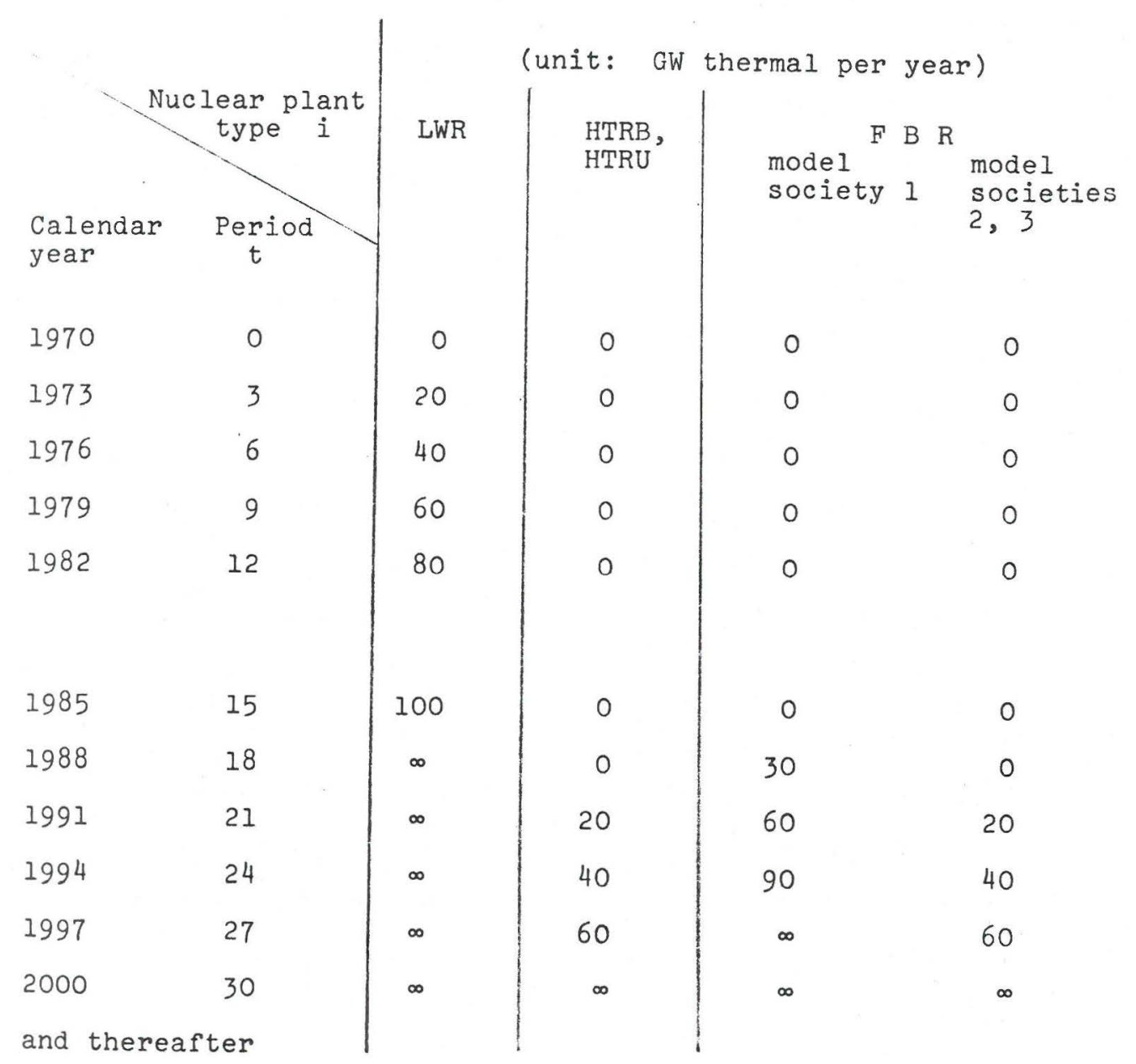


$25010^{6}$ persons and a per capita primary energy consumption rate of $10 \mathrm{~kW}$ thermal, with $25 \%$ of the total primary energy employed for producing electricity. Thus, the total primary energy is $2.500 \mathrm{TW}$ thermal, with $.625 \mathrm{TW}$ in the form of electricity and 1.8;5 TW of non-electric energy. ${ }^{13}$ As a further simplification, it will be supposed that coal provides all the primary energy for generating electricity, and that petroleum and gas (PETG) cover all the non-electric demands in year O (1970).

In model societies 1 and 2, the energy demands are exogenous throughout the planning horizon (see Figure 3 ). Both economies are planning for a slow-down in energy growth, but each in a somewhat different way. In society 1 , the demands are projected to follow third degree polynomial paths up to the year 2015, and then to remain constant. The parameters of the two polynomials are chosen so that: 1) the 1970 initial conditions are satisfied; 2) the 1970-73 growth rates for electric and non-electric energy are 8 and $4 \%$ per year respectively; and 4) the population increases by $50 \%$, and the per capita consumption doubles from 10 to $20 \mathrm{KW}$ between 1970 and 2015. From the latter point onward, electricity demands constitute $50 \%$ of the total primary energy.

$131 \mathrm{TW}=1$ terawatt $=10^{12}$ watts

$I \mathrm{GW}=1$ gigawatt $=10^{9}$ watts

$I \mathrm{TW}=.03 \mathrm{Q}$ units per year $=3010^{15}$ British thermal units (BTU's) per year

I Q unit $=10^{18}$ BTU's $=.2510^{18}$ kilocalories.

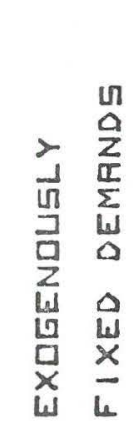

亡

$\underline{4}$

台台

. तै

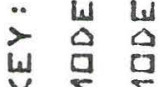

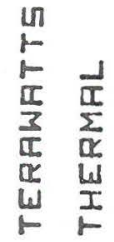

m

(1)

$r \quad 10$
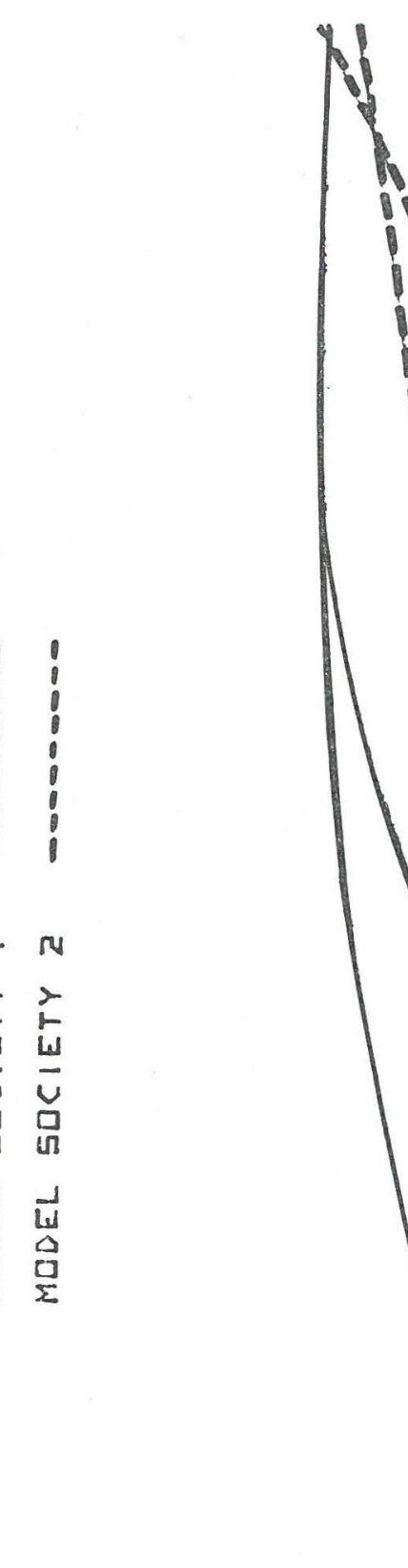

年 
Model society 2 follows an exponential growth path, hence does not reach saturation at any point. Here, however, the exponential growth rates are quite low: $3 \%$ and $1 \%$ per year for electric and non-electric energy respectively.

With these parameters, the exponential growth curves (society 2) lie below the limited growth case (society 1 ) virtually throughout the planning horizon.

In model society 3, it is supposed that demands are responsive to price. (For this reason, there can be no exogenous demand projections analogous to those of Figure 3.) Here the market demands are viewed as if they were the outcome of a "utility" maximizing process. ${ }^{14}$ The objective function is the maximization of the money value of consumers utility, less the costs of meeting the final demands.

Let the unknowns $q_{1}^{t}$ and $q_{2}^{t}$ denote the final demands for electric and non-electric energy, respectively, at time t. Then the total utility obtained over the planning horizon is expressed as

$$
U=\sum_{t=0}^{75} \sum_{j=1}^{2}\left[a_{j}^{t}\left(q_{j}^{t}\right)^{b}-c_{j}^{t}\right],
$$

where the parameters $a_{j}^{t}, b_{j}$, and $c_{j}^{t}$ are estimated through a series of assumptions concerning the demand curves for the

14 This formulation was originally suggested by Samuelson [14], who pointed out that a competitive partial equilibrium solution could be computed through an optimizing mod sum of consumers' and producers' surpluses is to be maximized. two types of energy at each point of time. Unless the exponents $\mathrm{b}_{j}$ equal unity, the utility function $U$ is a nonlinear one. The additively separable form implies that the demand for each item depends only upon its own marginal cost of supply, and that therefore the cross-elasticities with respect to all other prices are zero.

The utility function parameters are derived from the estimates of elasticities, reference quantities, and prices shown in Table $6 .{ }^{15}$ The reference quantities $\bar{q}_{j}^{t}$ are extrapolated from the 1970 initial values $\bar{q}_{j}^{0}$. With a 3\% annual GNP growth and an income elasticity of unity, the demands

$15_{\text {To }}$ estimate the parameters of the utility function $U$, we begin by noting that the exponent $b j$ is related to $\varepsilon j$, the own-price elasticity for item $j$, as

$$
b_{j}=1+\frac{1}{\varepsilon j} \text {. }
$$

our numerical estimates of the elasticities are shown in Table 6. These demands are more inelastic than appears to be suggested by the econometric work of Doctor et al. [4, p.38] for electricity and of Edmonson [5] for total energy. It should be recalled, however, that we are dealing with the derived demand for primary energy--not the consumers' demand It is to be expected that the derived demands will be less elastic than that of final consumers.

If the "reference" quantity $\bar{q}_{j}^{t}$ is the equilibrium level of demand at the reference price $p_{j}$, it can be shown that the parameter $a_{j}^{t}$ may be estimated as

$$
a_{j}^{t}=\frac{\bar{p}_{j}^{t}}{b_{j}\left(\bar{q}_{j}^{t}\right)^{b_{j}-1}}
$$

The constants $c_{j}^{t}$ do not affect the optimization directly. For comparability with the objective function values of model 
Table 6. Parameters for estimating market demand curves, model society 3 .

\begin{tabular}{|c|c|c|}
\hline index $j$ & 1 & 2 \\
\hline item & ELEC & NELE \\
\hline $\begin{array}{l}\text { own-price } \\
\text { elasticity, } \varepsilon j\end{array}$ & -.5 & -.3 \\
\hline $\begin{array}{l}\text { reference } \\
\text { quantity, } \\
\bar{q}_{j}^{t}=\bar{q}_{j}^{O}(1.03)^{t} \\
\text { (unit: Tw thermal) }\end{array}$ & $.625(1.03)^{t}$ & $1.875(1.03)^{t}$ \\
\hline $\begin{array}{l}\text { reference price, } \\
\bar{p}_{j}\end{array}$ & $\begin{array}{l}\$ 30 / \text { thermal KW-year } \\
=\$ 10 / 10^{3} \text { electrical } \\
\text { KW-hours }\end{array}$ & $\begin{array}{c}\$ 15 / \text { thermal KW-year }= \\
\$ 3 / \text { barrel of oil }= \\
\$ .50 / \text { million BTU of } \\
\text { natural gas }\end{array}$ \\
\hline
\end{tabular}

society 2 , it is convenient to choose these constants so that

$$
c_{j}^{t}=a_{j}^{t}\left(\bar{r}_{j}^{t}\right)^{b} \text {, }
$$

where $\bar{r}_{j}^{t}$ are the exogenous requirements stipulated for that associated with satisfying the demands of model society 2

Once the parameters $a_{j}^{t}, b_{j}^{t}$, and $c_{j}^{t}$, have been selected, nonlinear function U is approximated by the sum of piecewise linear functions. For the approximation, the grid points were chosen so as to match with annual growth rates of 1,2 , 3 , 4 , and $5 \%$ starting from the initial gevels of demand for see Manne [10]. will grow exponentially at the compound annual rate of $3 \%$ provided that future prices remain constant at the 1970 levels $p_{j}^{0}$. Note two further details: 1) the future reference prices $p_{j}^{t}$ must be converted into present values through the present value factor $\beta^{t}$; and 2) the annual prices must be converted into 3-year prices for each time period--just as is done in the objective function row of the programming submatrix, Table 4.

To see the implications of the numerical parameters adopted for society 3, recall that we have assumed the supply cost of petroleum and gas (PETG) to be $\$ 10$ per barrel throughout the planning horizon subsequent to 1970. With a price elasticity of -.3 and a reference price of $\$ 3$ per barrel for non-electric energy, this would imply an immediate drop in demand to $(10 / 3)^{-.3}=70 \%$ of the reference level. To avoid such an unrealistic short-run cutback, we have therefore imposed an additional constraint: the non-electric energy demands can at no time drop below the $1 \%$ growth projection adopted for model society 2. It will be seen below that this lower bound is an effective constraint until the HTRB water splitting technology becomes available in the 1990's.

\section{Resource Availabilities}

There is no easy way to define--let alone measure-the availability of fuel resources. As soon as one examines the footnotes attached to each of the well-known estimates, the ambiguities become apparent. Only the cartoon character 
Charlie Brown can be safe, for he says "I'm always sure about things that are a matter of opinion."

The ambiguities are least when referring to "proven reserves." Typical of current estimates is Table 7, adapted from the energy work of the Pestel and Mesarovic world modeling project. Several features of this table are striking: a) the high proportion (over 50\%) of the world's oil and gas reserves located in the Middle East; b) the low proportion of oil and gas (15\%) in the principal consuming countries of North America, Western Europe and Japan; and

c) the estimate that the world's ratio of oil and gas reserves to production is on the order of 40 years.

In themselves, these ratios do not spell Doomsday for oil importers. It is risky, however, for these countries not to begin to convert their vast resources of oil shale and coal into synthetic fuels. Both shale and coal are dirty to extract and to process. To meet reasonable environmental standards, they will probably cost $\$ 10$ per barrel of crude oil equivalent. It is to allow for these sources that the cost of PETG is taken to be $\$ 10$ per barrel for our model societies. These supplies are the world's marginal sources-not the Middle East where production costs lie well below \$1 per barrel.

For each model society, the initial level of PETG consumption is $1.875 \mathrm{TW}=.056 \mathrm{Q}$ units per year $=35 \%$ of the world's entire 1970 production of oil and gas. If this
Table 7. World's proven reserves and production of fossil fuels (Q units $=10^{18} \mathrm{BTU}$ ) ${ }^{(\mathrm{a})}$.

\begin{tabular}{|c|c|c|c|c|c|c|}
\hline \multicolumn{2}{|c|}{ Region } & oil(b) & $\begin{array}{c}\mathrm{Re} \\
\operatorname{gas}(\mathrm{c})\end{array}$ & $\begin{array}{l}\text { S e } r \text { v } \\
\text { oil and } \\
\text { gas }\end{array}$ & \multicolumn{2}{|c|}{$\operatorname{shale}_{(d)}(\operatorname{coal}(e)$} \\
\hline 1 & North America & .28 & .32 & .60 & 2.5 & 21 \\
\hline 2 & Western Europe & .08 & .18 & .26 & & 4 \\
\hline 3 & Japan & 0 & 0 & 0 & & 0 \\
\hline 4 & Other developed & $\operatorname{lns}^{01}$ & .05 & .06 & & 3 \\
\hline 5 & Eastern Europe nation & $\begin{array}{l}0.57 \\
.47\end{array}$ & .64 & 1.11 & & 72 \\
\hline 6 & Latin America & .20 & .08 & .28 & & 0 \\
\hline 7 & Middle East & 2.63 & .48 & 3.11 & & 0 \\
\hline 8 & Main Africa & .14 & .05 & .19 & & 0 \\
\hline & South East Asia & .08 & .05 & .13 & & 2 \\
\hline 10 & China & .12 & .02 & .14 & & 23 \\
\hline & World reserves & $\overline{4.01}$ & $\overline{1.87}$ & $\overline{5.88}$ & $\overline{4.1}$ & $\overline{125}$ \\
\hline & $\begin{array}{l}1970 \text { world } \\
\text { production }\end{array}$ & .11 & .05 & .16 & 0 & .07 \\
\hline & $\begin{array}{l}\text { Ratio of reserves } \\
\text { to production(years) }\end{array}$ & $\approx 40$ & $\approx 40$ & $\approx 40$ & $\infty$ & $\approx 2000$ \\
\hline
\end{tabular}

Notes:

(a) Source: Bauerschmidt et al. [3].

(b) Proven reserves of oil. Conversion factor: 6 million BTU per barrel.

(c) Proven reserves of gas. Conversion factor: 35,000 BTU per cubic meter.

(d) Identified reserves of shale oil. In addition, it is estimated that there are 300 billion barrels $=1.8 \mathrm{Q}$ units reserves is tar sands. Geographical breakdown of shale America. Conversion factor. 6 million BTU pertside North

(e) Measured + identified reserves of co Conversion factor: 28 million BTU per metric ton of coal 
society is lucky enough to discover new domestic resources (say, 5 fields the size of the North Sea or of Alaska's Northern Slope), there are no difficult tradeoffs between political autonomy, economic costs, and environmental goals. In the U.S., for example, energy resources would be a nonproblem if the $4.8 \mathrm{Q}$ units of "undiscovered recoverable" oil and gas could somehow be discovered. It would also help if the $1.9 \mathrm{Q}$ units of "identified submarginal" resources were available at a cost of, say, less than $\$ 10$ per barrel. These are possibilities--but not certainties-- according to the U.S. Geological Survey's estimates reproduced in Table 8 ,

It is just as difficult to estimate the availability of uranium as that of oil and gas. For the U.S., there are data indicating that 1-2 million tons of uranium might be available at an extraction cost of $\$ 15$ per pound or less. ${ }^{16}$ Outside the U.S., the world is less well explored. The situation is even more complex if we attempt to estimate the amounts available at a cost above $\$ 15$ per pound.

To avoid overstating the case for the FBR, it seemed preferable to err on the high side and to suppose that there are 2 million metric tons of low cost uranium ( $\$ 15$ per pound) available for our model society. No upper limit has been

${ }^{16}$ For U.S. Geological Survey estimates, see McKelvey and Duncan [13], and also Theobald et al. [16, pp.23, 24].
Tabie 8. Fossil fuel resources of the United States. (a) $\left(Q \cdot\right.$ nits $\left.=10^{18} \mathrm{BTU}\right)$

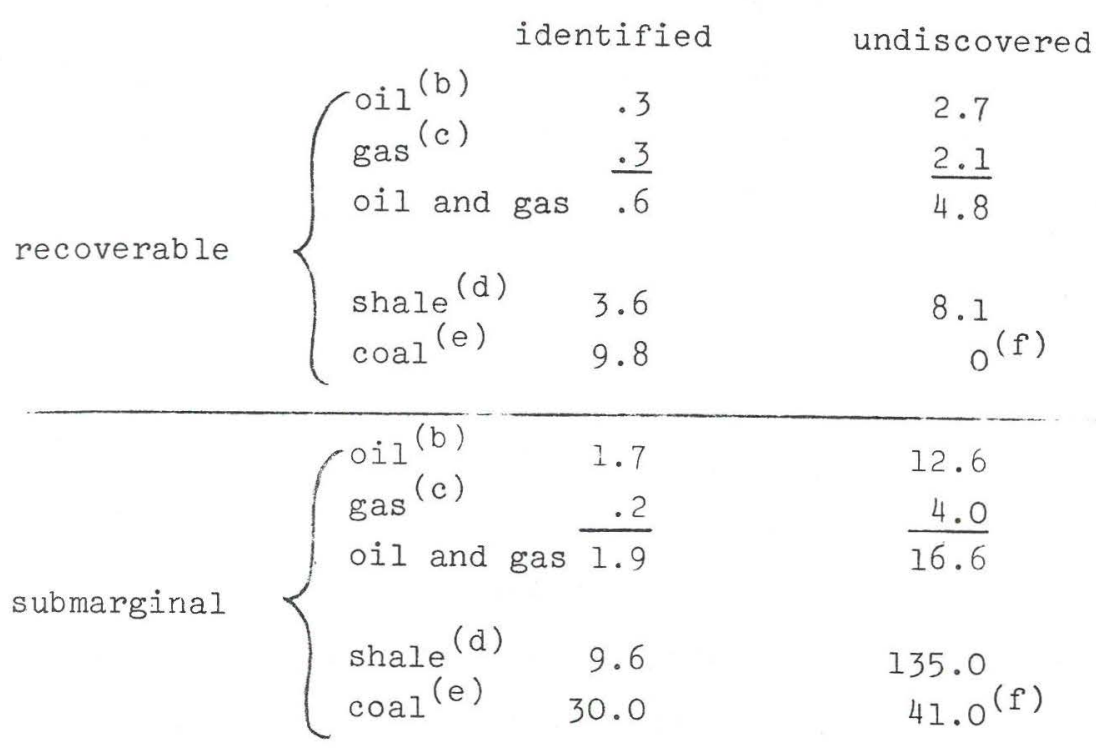

Notes:

(a) Source: Theobald et al. [16].

(b) Crude oil and natural gas liquids; includes Alaska and continental margin to $2500 \mathrm{~m}$ water depth, as of December 31, 1970. Conversion factor: 6 million BTU

(c) Includes Aia

depth, as of December 3 inental margin to $2500 \mathrm{~m}$ water depth, as of December 31, 1970. Conversion factor:

(d) "Recoverable" includes all oil shale classed as "par marginal" in 1972. Conversion factor: 6 million BTU

e) barrel. 25 million BTU per short ton.

f) Source provides no breakdown between recoverable and submarginal undiscovered coal resources. 
imposed for the supply of high cost material ( $\$ 50$ per pound). In Table 10 below, it will be seen that the demands for ore lie within reasonable limits--no more than 6.6 million tons cumulated through 2030. This depends, of course, upon the assumption that the FBR will be introduced on a large scale during the early 1990's, and that this technology will be employed to replace LWR's at the end of their 30-year service lives.

\section{Conclusions--Timing}

This paper has focused on timing the introduction of new technologies, taking a perspective sufficiently long so as to allow for the eventual exhaustion of oil and gas resources. For this purpose, it is a convenient simplification to work with a "static" index: the ratio between the reserves of PETG and the annual consumption rate during the base year, 1970. Our calculations are based upon three alternatives: 40, 60, or 80 "years" of reserves. Translated into BTU's, this means $2.250,3.375$, or $4.500 \mathrm{Q}$ units.

To understand the magnitude of these fuel supplies, it is worth recalling (from Table 7) that the entire world's proven reserves of oil and gas are today only 6 Q units. Now suppose that model society I (Table 10) has no other source of non-electrical energy but oil and gas. Suppose also that the world's entire proven reserves were placed at the disposal of this society, without allowing for consumption anywhere else. These oil and gas supplies would still he exhausted by the year 2030 (in Table 10, see the column headed "no nuclear, unlimited PETG"). To rely only upon fossil fuels, this society would have to set up a large new industry for converting coal and shale into synthetic hydrocarbons. Although these synthesis processes do not appear explicitly in our programming matrix, they do appear implicitly when it is assumed that any one nation might be planning to consume more than $3 \mathrm{Q}$ units' worth of PETG resources.

In all, we have studied three different model societies and three levels of PETG availability, nine logically possible base cases. To distinguish these, we shall employ a two-digit number. The first will identify the model society's demand curves and rate of introduction of the FBR (recall Figure 3 and Table 5). The second digit will identify the number of years of PETG resources. For example, case 1.60 refers to model society 1 with 60 years of these resources.

Our principal conclusions are as follows:

A. The static index provides a rough approximation to the ending date for the period of dependence upon oil and gas (see Figures $4 \mathrm{a}$ and $4 \mathrm{~b}$ ). For a smooth transition, new technologies must be introduced well in advance of these dates. By the year 2000, it will be necessary for hydrogen (or other synthetic fuels) to provide a substantial share of non-electric energy. In cases 1.60 and 2.60, this share would be $26 \%$ and $14 \%$ respectively. This would not be an easy task, either from the viewpoint of hydrogen supplies 


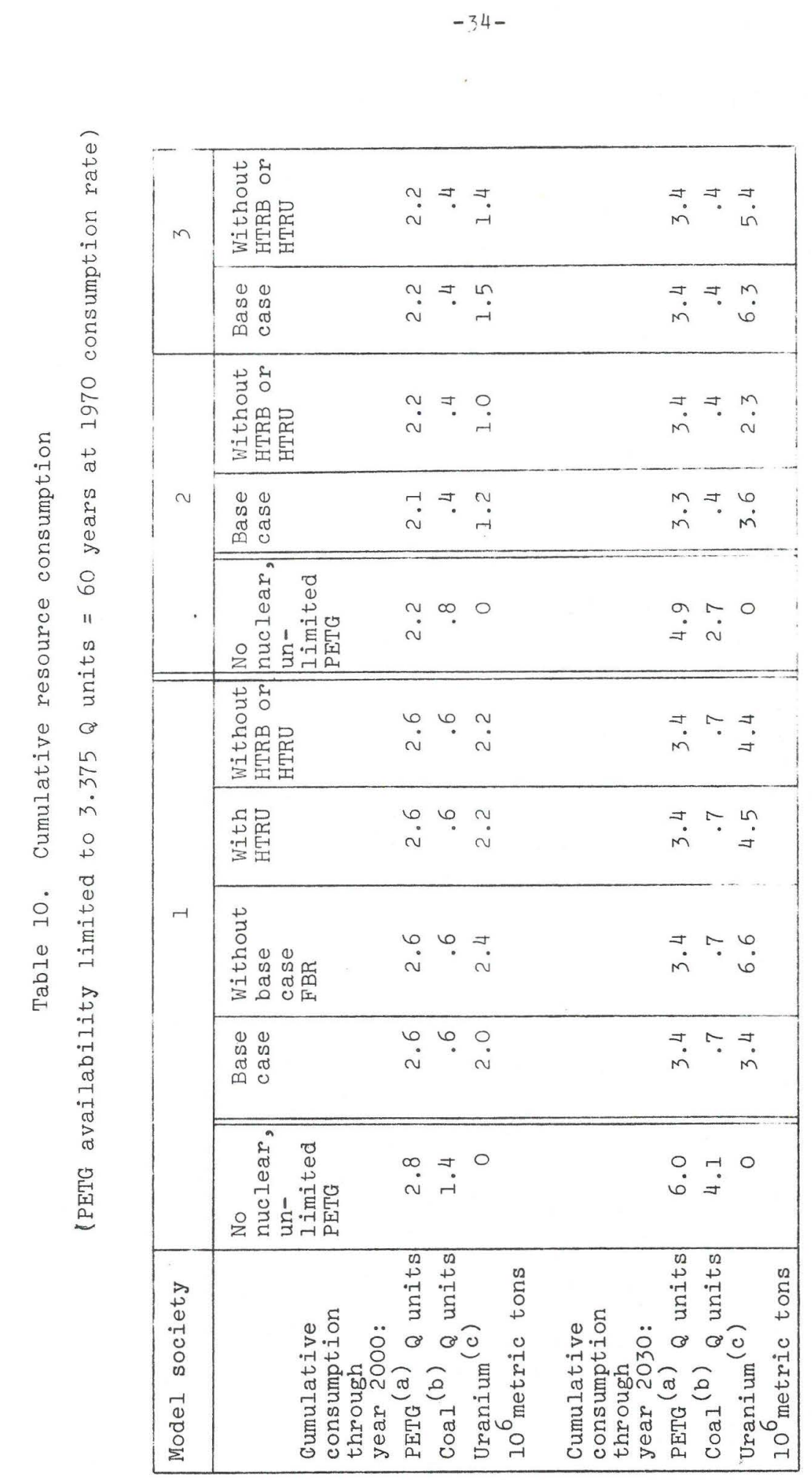
$\ddot{0}$
0
$\stackrel{0}{0}$
$\ddot{z}$

${ }^{17}$ Recall that the secondary energy output from electrolyzers is only $40 \%$ of the primary energy input into their associated LWR's. This is why the amounts of electrolytic hydrogen shown on Figures $5 a, 6 a$ and $7 a$ are on $1 y$ 40\% of the shown in Figy inputs $6 \mathrm{~b}$ and $7 \mathrm{~b}$ as the excess supplies over final demands, excluding electrolysis.

or from that of utilization devices. The task would become -ill more difficult--and is probably infeasible--in case 1.40. There hylrogen's share would have to be $62 \%$ by the year 2000. By contrast, if there is as much as 80 years' worth of PETG available to these societies, there are no critical limits on fuel supply. The pace of transition can be far more leisurely than with 40-60 years of reserves.

B. The curves of installed capacity (Figures 5-7) follow a smooth pattern over time, both for electrical and non-electrical energy production. During the period when petroleum and gas production begin to drop, hydrogen comes in to take its place. Most of the hydrogen is produced by the HTRB process, but some by electrolysis, depending on the relative scarcity of breeding gain and of oil and gas reserves. In the case of electrical energy, it is optimal to phase out coal-fired plants between 2000 and 2015. LWR's continue to be needed until well after the year 2015, partly for their plutonium output and partly for electricity ${ }^{17}$.

c. According to our model, there are constraints upon the initial rates of construction of nuclear reactors. In model society 1 , these constraints for the FBR are released 
Figure $4 a$.
HYDROEEN, PERCENT

HYOREEEN, PERCENT

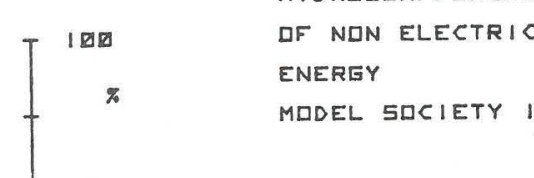

붕

f

-

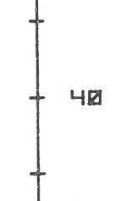

-20

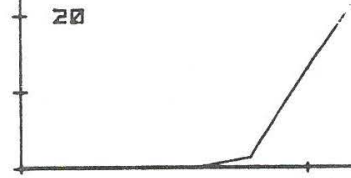

1970

2000
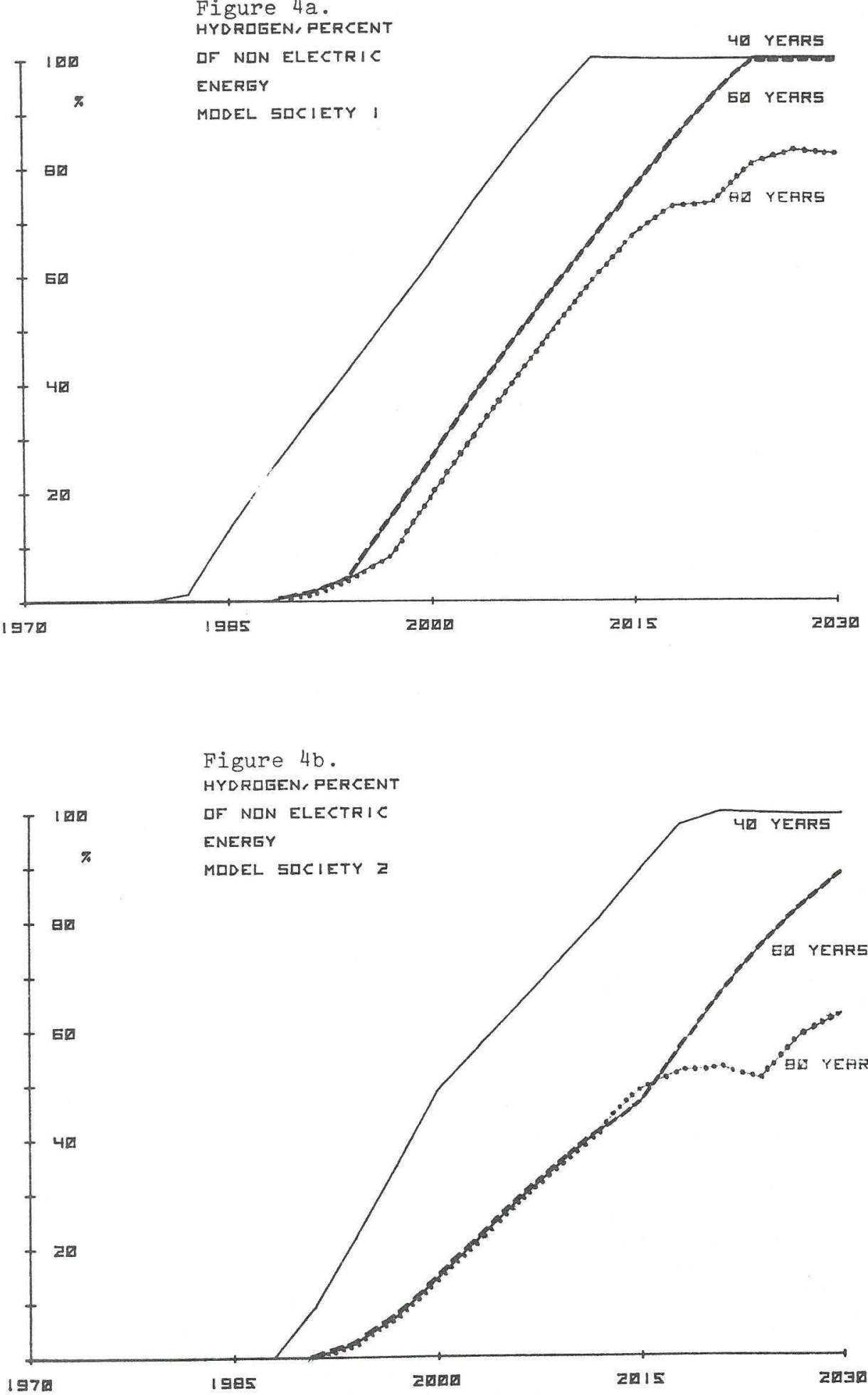

20

1970

Figure 4b.

HYDRIEEN, PERCENT

DF NDN ELECTRIC

ENERE

2015

2030

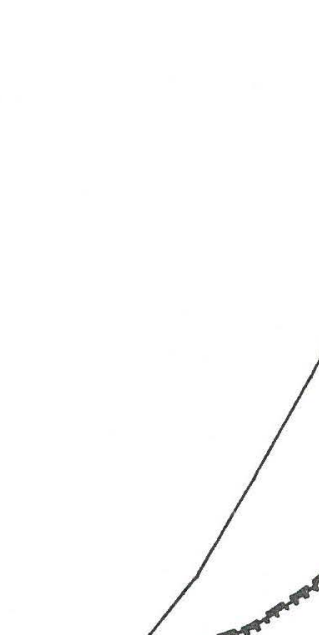

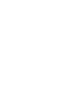
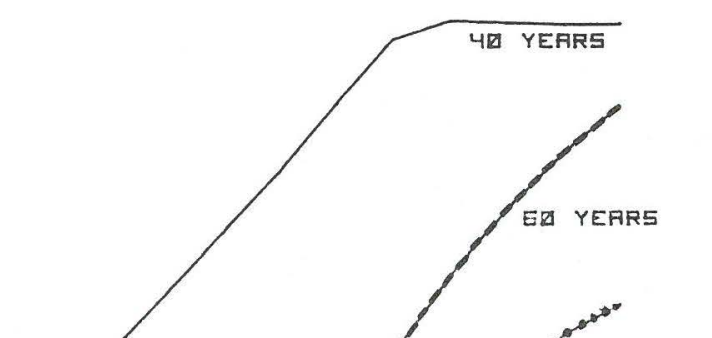

1985

20खण
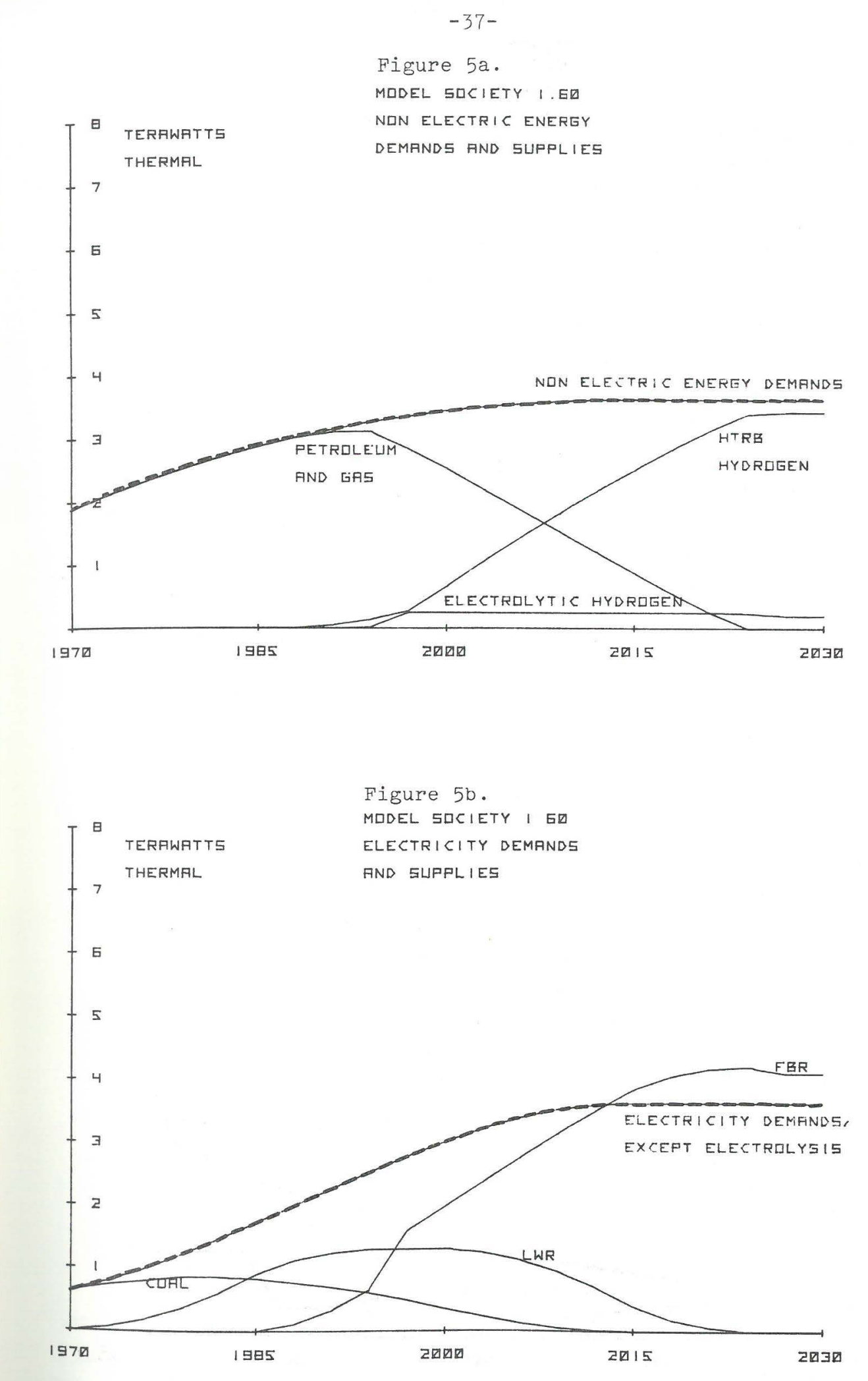
Figure 6a.
MDDEL SDCIETY 2.E

NIN ELECTRIC ENEREY

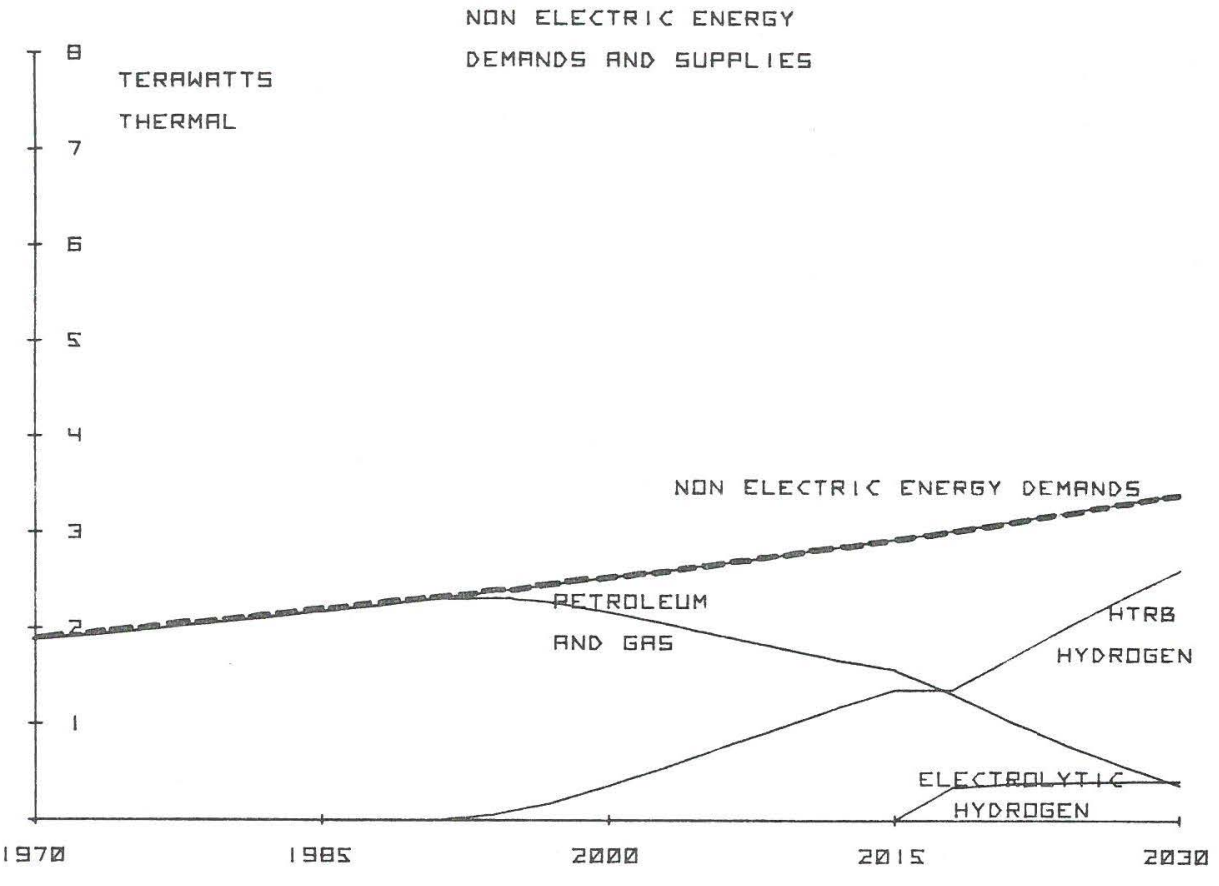

Figure 6b.

MLOEL SOCIETY 2 .EU

ELECTRICITY DEMANDS

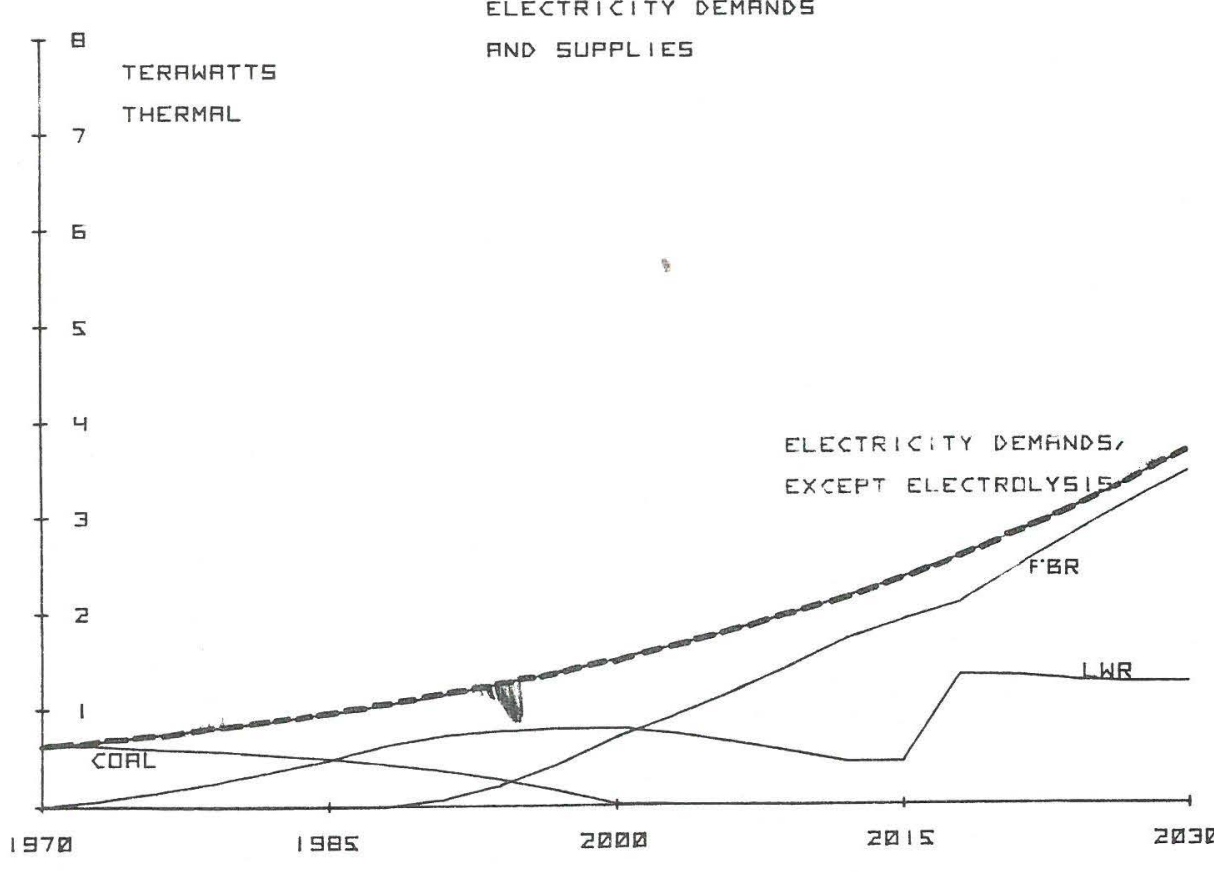

Figure $7 \mathrm{a}$.

$1.4 \square$

NDN ELECTRIC ENEREY

DEMANDS FND SUPPLIES

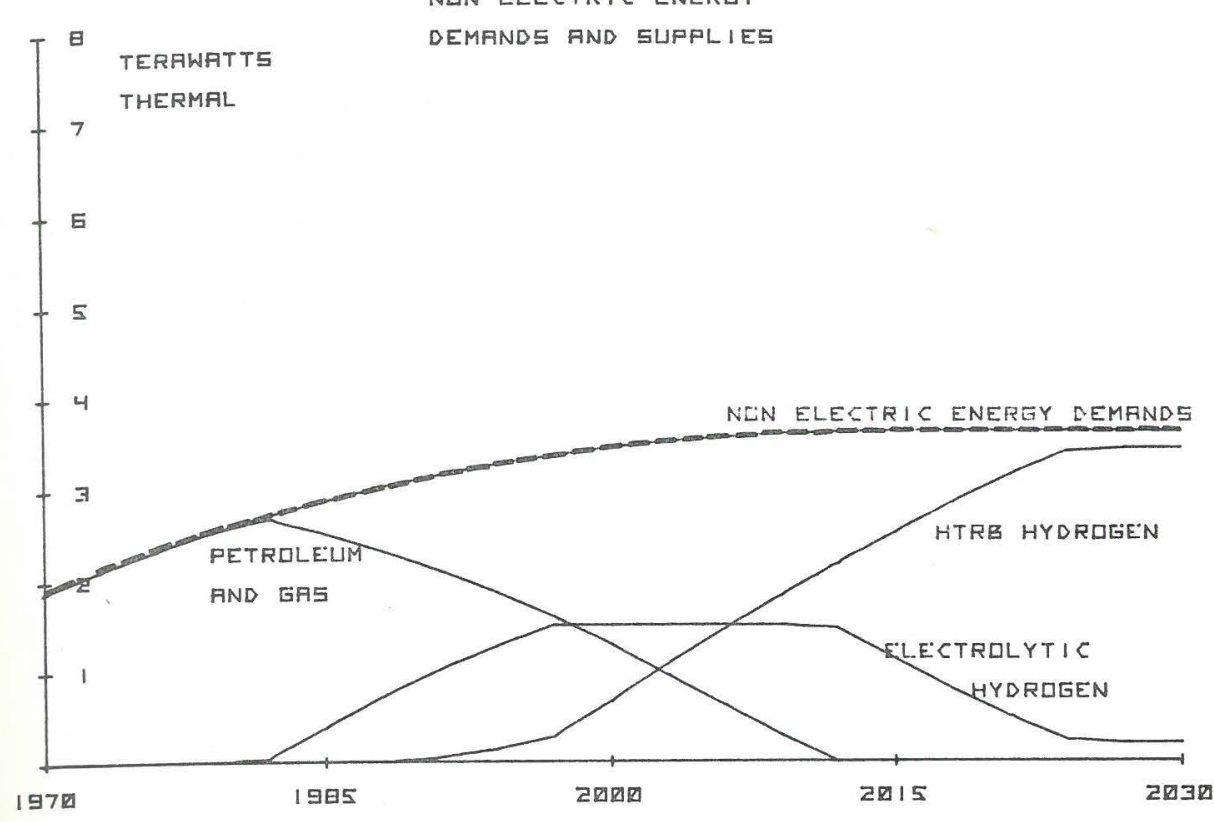

Figure $7 \mathrm{~b}$.

MDDEL SDCIETY 1.40

ELECTRICITY DEM
AND SUPPLIES

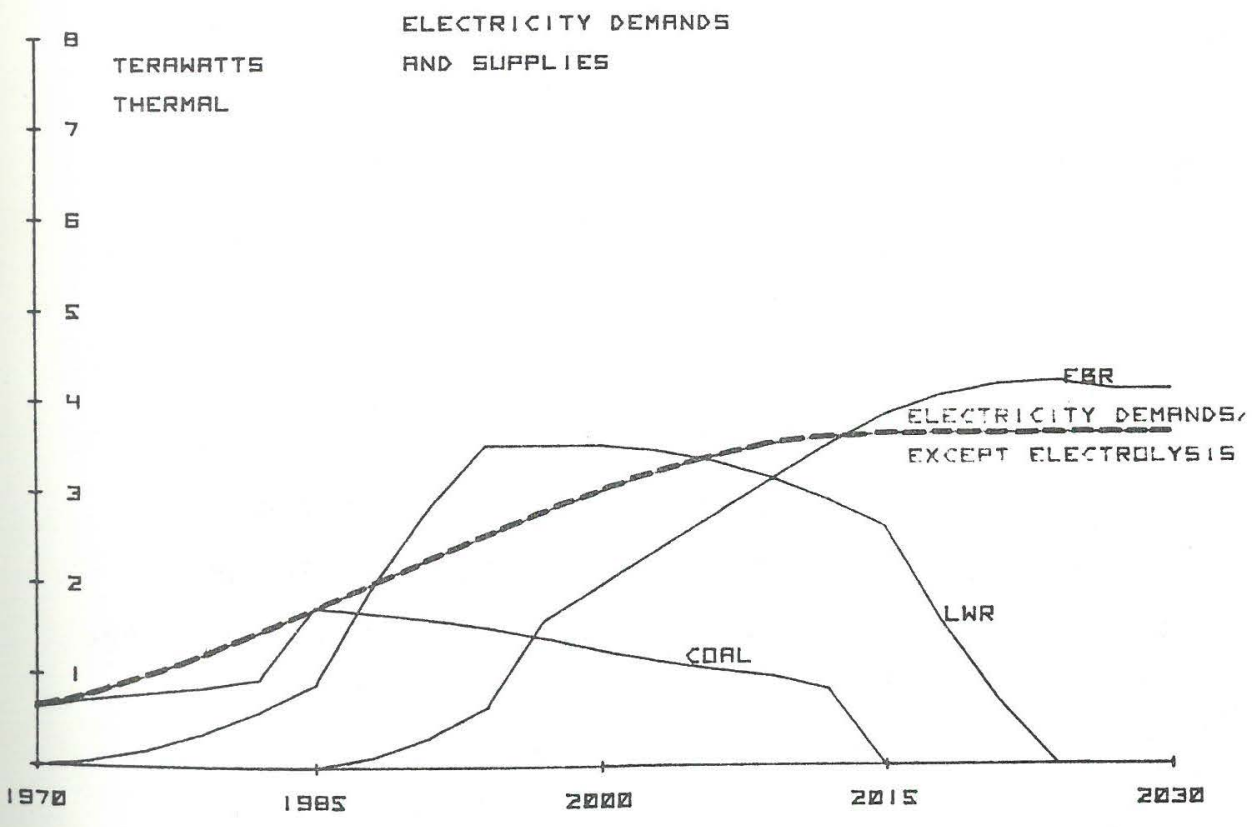


after the year 1994 (see Table 5). There is then an immediate--and somewhat unrealistic--boom in FBR construction during the following time period (this is echoed 30 years later, exactly at the end of the service life of these stations). The boom in FBR's is matched by a precipitous decline in LWR construction if one follows Figure D-la (Appendix D) quite literally. In reality, one could plan for a smoother phasing of these construction activities through the investment decisions to be taken in the early $1980^{\prime}$ s.

D. There are serious difficulties with case 1.40. The shortages of oil and gas are so severe that it is optimal to construct large numbers of LWR's just as soon as their construction constraints are released in 1988. There is then a spurt in the construction of LWR's to provide base load energy for electrolytic hydrogen production. The LWR's and the electrolysis plants remain in service during the following 30 years--even though the more economical thermochemical water splitting process becomes available meanwhile. The severe shortages of oil and gas lead to an overreaction within the energy sector, and this is another symptom of the criticality of the situation (Figure D-2a).

E. The plutonium stockpile and its incremental value (or dual variable) provides an index of the abundance or scarcity of breeding gain (Figures D-3a, b). In case 1.60, there is virtually always a positive stockpile, and so the incremental value of plutonium is zero. In case 2.60 --or in 1.60 with a less advanced FBR (the conventional oxide type) --the plutonium stockpile drops to zero shortly after the introduction of FBR's. This leads to a rapidly rising incremental value for plutonium. One should be quite cautious in interpreting the incremental values ascribed here, for this will depend heavily upon the reactor mix, rate of growth of demand, etc. Nontheless, Figure D-3b suggests that substantial benefits are possible from international trade in plutonium if it should turn out that the FBR is adopted rapidly in one country but not in another.

\section{Conclusions--Technological Assessments}

In order to make economic comparisons between alternative technologies, we shall rely upon the objective function --the present value of costs less benefits. For all 9 base cases, the value of the objective function is given in the first three lines of Table 9. These values are not meaningful in themselves. They are dominated by a fixed component: the present value of costs incurred during the initial 15year period when there are virtually no technological choices to be made. In case 1.60, for example, the costs during this period constitute $54 \%$ of the total of $\$ 850$ billions. Because of this large fixed component, it is a more meaningful yardstick to compare the benefits of new nuclear technologies with their research and development costs. One can also make comparisons with the benefits to be obtained from additional oil and gas resources. If, for example, there were to be 80 instead of 40 years' worth of PETG available to 


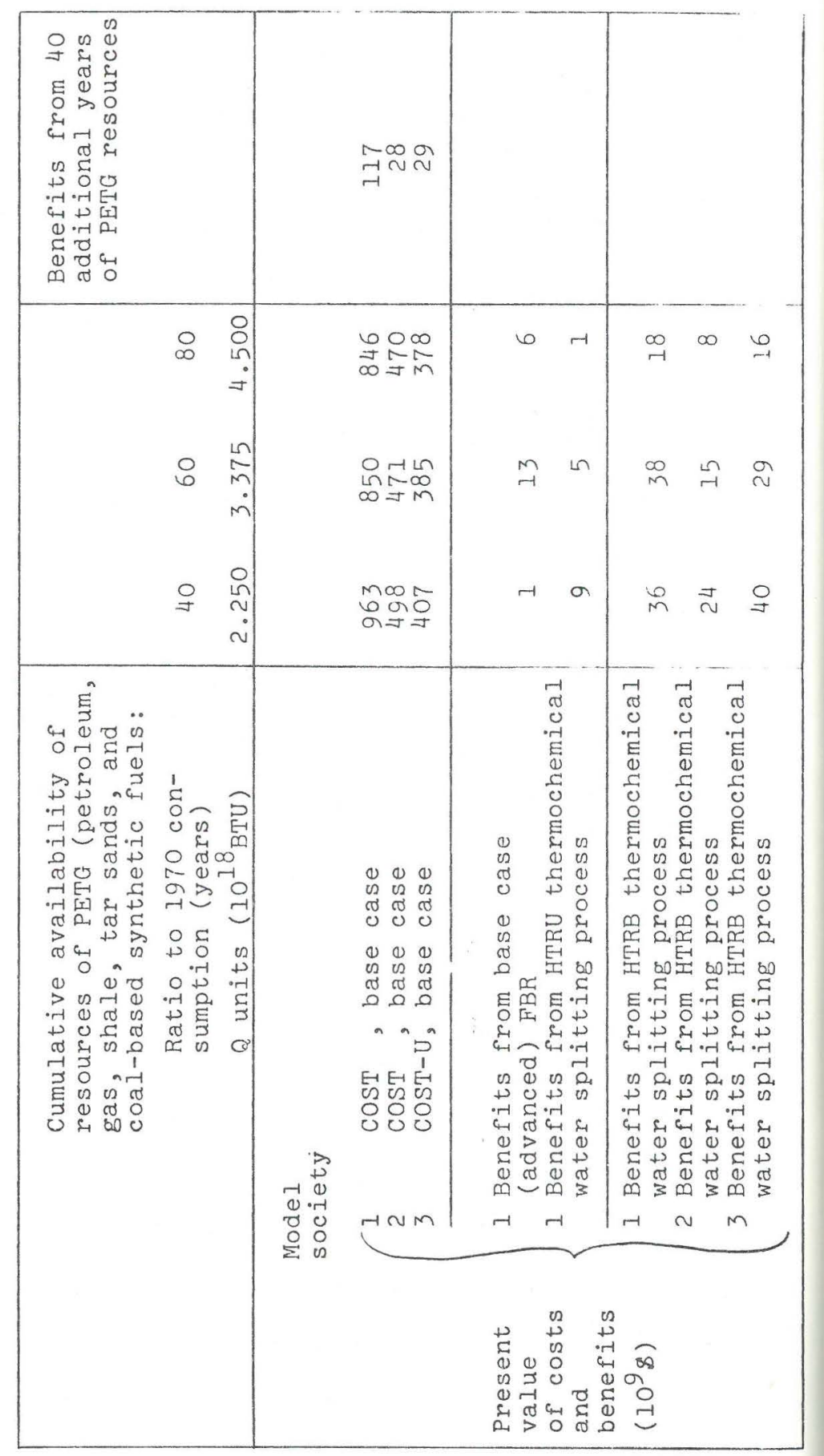

model society 1 , these additional resources would have a present value of $\$ 117=\$ 963-846$ billion (see the rightmost column of Table 9). 18

To calculate the benefits of new technologies, we have run a series of variants upon the base cases. For example, in the absence of the HTRB thermochemical water splitting process, it would become necessary to produce all hydrogen through base load electrolysis. Costs would then rise to $\$ 888$ billion in society 1.60 . With the HTRB technology, the cost savings are $\$ 38=\$ 888-850$ billion. In general, our conclusions are as follows:

A. The benefits are interdependent with the level of demand and the level of PETG resources. The more optimistic the forecast of oil availability, the lower becomes the incentive to develop water splitting technologies. In the least favorable case (society 2.80), the benefits are $\$ 8$ billion. With an incentive of this magnitude, it would still pay to investigate 100 thermochemical cycles in parallel--even if each preliminary investigation were to have only a $1 \%$ chance of success and a cost of $\$ 10$ million (see Manne and Marchetti [1]]).

${ }^{18}$ Both between cases 1.40 and $1.60--a n d$ again between 1.60 and $1.80--$ there is a difference of $1.125 \mathrm{Q}$ units in the availability of oil and gas. In the one case, this leads to a cost reduction of $\$ 113$ billion, and in the other than 60 years' worth of PETG resources were really available, there would be no critical bottleneck in the supply of fossil fuels. 
B. In Figure 8, we plot the time shape of the cumulated benefits for societies $1.60,2.60$, and 3.60. In the first of these cases, it has already been noted that the benefits would be $\$ 38$ billion over the 75-year planning horizon, and that none accrue before 1985. Figure 8 shows that virtually the entire benefits of the HTRB would be obtained between the years 1985 and 2015. With a 10\% discount rate, the incentive to develop this technology does not depend strongly upon subsequent events, e.g. the possible introduction of fusion or the rate of growth of demand after 2015. In this way, discounting reduces the effect of the errors that are inevitably associated with 50 or 75 -year projections.

C. Two additional technology assessments are provided in Table 9--the $\underline{\text { HTRU }}^{19}$ option for thermochemical water splitting and also the base case (advanced) breeder versus the conventional oxide FBR. For both of these alternatives, the present value of benefits is positive, but not as large as for the HTRB. In case 1.60 , there would be a saving of $\$ 13$ billion if the conventional FBR design of the 1970's were replaced by the more advanced breeder. This benefit does not show up in case 1.40, for here the energy sector is

${ }^{19}$ With the HTRU, it is optimal to eliminate electrolysis completely. It then turns out that breeding gain and plutonium have a positive value. For the year 2000, the gram. (Compare with Figure D-3b.)

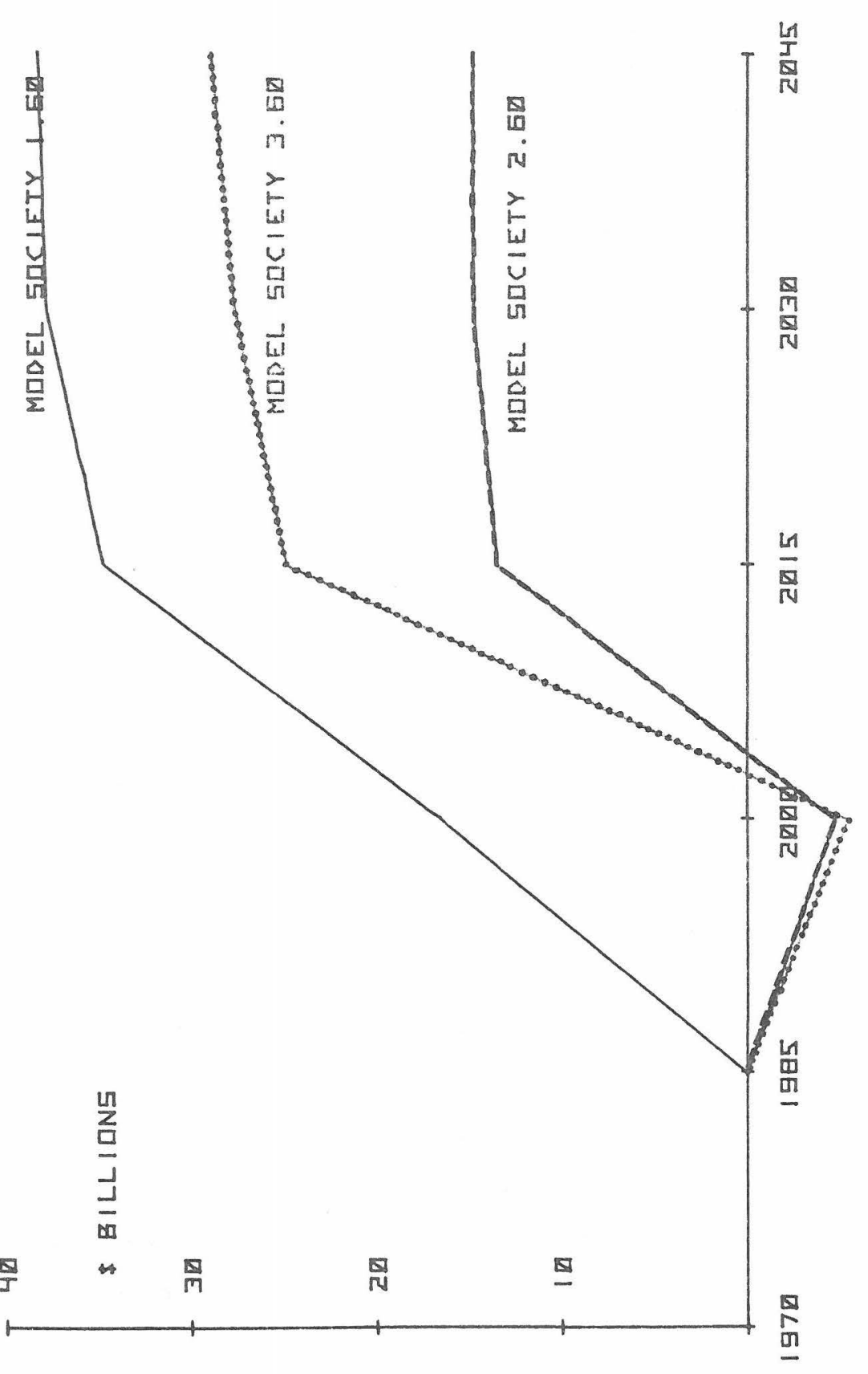


required to install large numbers of LWR's immediately after 1985. This cancels many of the benefits that might otherwise be obtained through the FBR. The conclusion follows logically from the premises, but it provides one more clue that case 1.40 is an inconsistent one. Either the PETG supplies must be increased, or the growth of demand must be reduced.

D. Model society 2 provides an informative contrast to society 1. Here--until the year 2015--the FBR capacity is built up smoothly, following the slow but steady increases in demand. In the year 2015, the plutonium stockpile finally drops to zero, and there is a short-lived boom in LWR construction. The shortage of breeding gain inhibits the construction of HTRB's and, in turn leads to an increase in electrolytic hydrogen production. This scenario should not be taken too seriously, but it does indicate the logical difficulties in setting up either an optimization or a simulation model in which all prices and quantities are to follow smooth trajectories. The reader is urged to follow only the broad trend lines, and to filter out some of these short-run aberrations, especially those occurring in the distant future.

E. Model society 3 allows for price responsive demands. Here the quantities grow less smoothly than in societies 1 and 2, but the shadow prices (incremental costs) grow more smoothly (compare Tables 11 and 12). In model society 3, note that the equilibrium solution is for non-electric energy de-
Table 11. Model society 3 - price responsive final demands.*

\begin{tabular}{|c|c|c|}
\hline $\begin{array}{l}\text { Technology } \\
\text { available }\end{array}$ & $\begin{array}{l}\text { Base } \\
\text { case }\end{array}$ & $\begin{array}{l}\text { Without HTRB } \\
\text { or HTRU thermo- } \\
\text { chemical water } \\
\text { splitting }\end{array}$ \\
\hline $\begin{array}{l}\text { Electric energy demands } \\
\left(\mathrm{TW}_{\mathrm{th}}\right) \quad 1970\end{array}$ & .62 & .62 \\
\hline 1985 & .97 & .97 \\
\hline 2000 & 1.52 & 1.52 \\
\hline 2015 & 2.36 & 2.36 \\
\hline 2030 & 3.76 & 3.68 \\
\hline $\begin{array}{l}\text { Non-electric energy } \\
\text { demands } 1970 \\
\left(\text { TW }_{t h}\right)\end{array}$ & 1.88 & 1.88 \\
\hline th 1985 & 2.18 & 2.18 \\
\hline 2000 & 3.22 & 2.77 \\
\hline 2015 & 4.57 & 4.57 \\
\hline 2030 & 6.15 & 6.15 \\
\hline 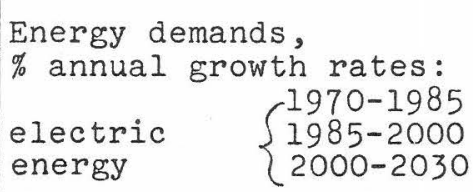 & $\begin{array}{l}3.0 \\
3.0 \\
3.1\end{array}$ & $\begin{array}{l}3.0 \\
3.0 \\
3.0\end{array}$ \\
\hline $\begin{array}{l}\text { non-electric } \\
\text { energy }\end{array}\left\{\begin{array}{l}1970-1985 \\
1985-2000 \\
2000-2030\end{array}\right.$ & $\begin{array}{l}1.0 \\
2.6 \\
2.2\end{array}$ & $\begin{array}{l}1.0 \\
1.6 \\
2.7\end{array}$ \\
\hline
\end{tabular}

Note:

${ }^{2}$ PETG availability limited to $3.375 \mathrm{Q}$ units $=60$ years at 1970 consumption rates. 


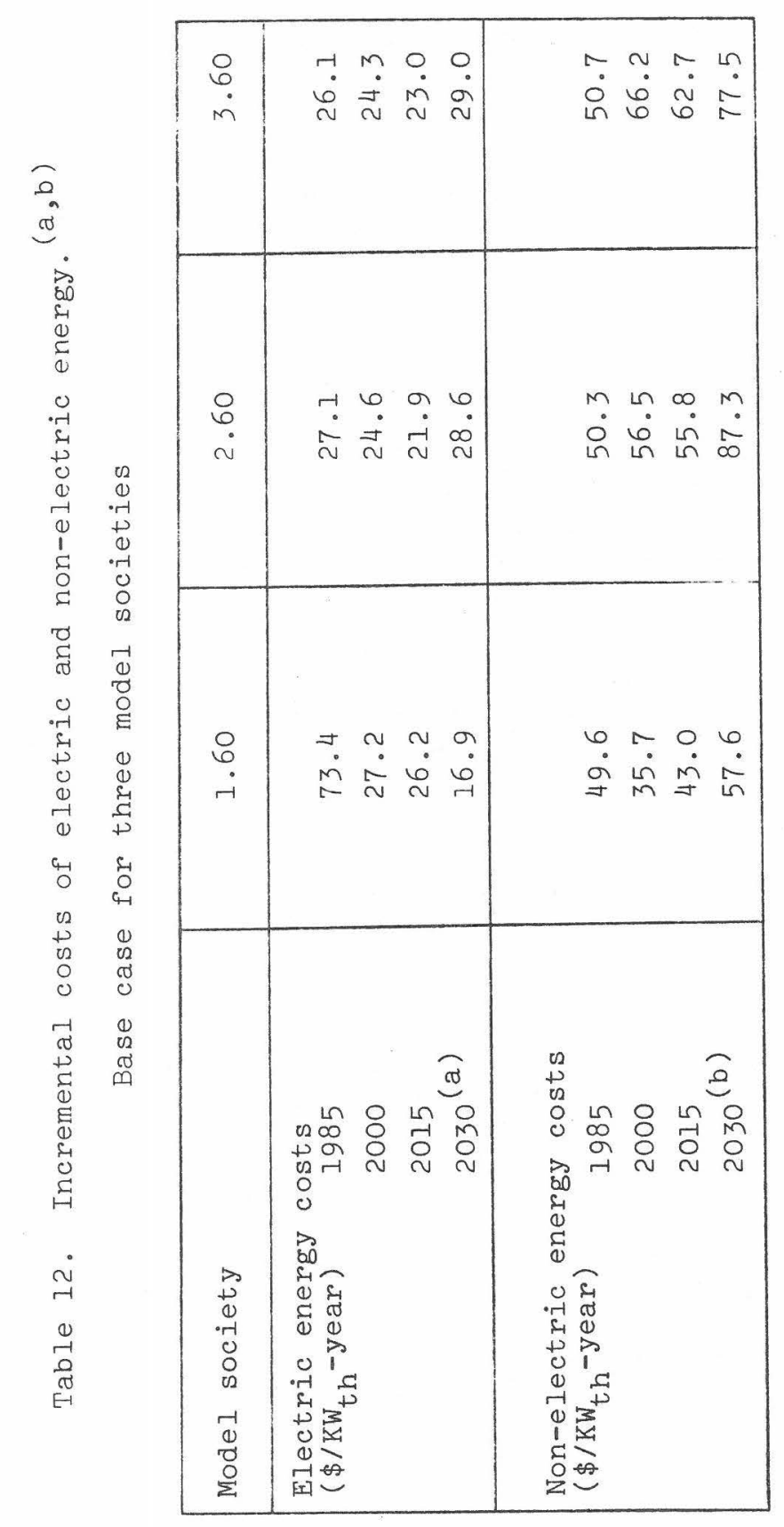

mands to grow at the lowest possible rate ( $1 \%$ per year) during 1970-85, but to accelerate during the following periods when thermochemical water splitting becomes available. This is a fairly clear illustration of interdependence between demands and the costs of supply.

F. From the incremental costs shown in Table 12, one can arrive at break-even values for the possible introduction of technologies not included in our model. For example, for society 1.60, the incremental cost of electricity in 2015 is shown as $\$ 26.2 / \mathrm{KW}_{\mathrm{th}}$-year. Allowing for an LWR electrical efficiency factor of $33 \%$ and a $10 \%$ annual discount rate, this implies that the break-even capital cost for a new technology would be $26.2 \div[(.33)(.10)] \approx \$ 800 / \mathrm{kW}$ electrical. This is the maximum that can be afforded for fusion or solar electricity, unless these new sources of primary energy are to have higher costs than nuclear fuels. The higher costs may be worth incurring on environmental or safety grounds, but this would lead to an entirely different set of considerations than the economic objectives and natural resource constraints analyzed here. 
Appendix A. Constraints

Units of measurement: $\mathrm{TW}_{\mathrm{th}}=$ terawatts thermal $=10^{12}$ watts

thermal of primary energy input

$C P_{i}^{t}$ - capacities, energy sector ( $\left.j=C O A L, \ldots, E L H Y\right)$

[apacity $]$ and production, $]=\left[\begin{array}{l}\text { capacity and } \\ \text { production, }\end{array}\right.$

current period

production,

3 years pre-
viously

annual capac-

$P C_{i}^{t}$

$=P C_{i}^{t-3}$

$+3 \quad$ i

ity increase,
current period

annual capac-

ment, after

30 years of

$+3$

$\left[D P_{i}^{t}\right.$

$-\mathrm{DP}_{i}^{t-30}$ Upper bounds on reactor construction rates $\mathrm{DP}_{i}^{t}$
$(i=\mathrm{i}$, FBR, HTRB, HTRU $)$

To represent limitations on the availability and rate of adoption of new technologies, upper bounds are imposed upon the annual construction rates of nuclear reactor capacity. See Table 5) 
$\mathrm{SM}_{j}^{t}-$ cumulative sums $(j=\mathrm{COAL}, \mathrm{PETG}, \mathrm{NU}, \mathrm{PLUT})$

$$
\begin{aligned}
& {\left[\begin{array}{l}
\text { cumulative } \\
\text { sum end } \\
\text { f }
\end{array}\right]=\left[\begin{array}{l}
\text { cumulative } \\
\text { sum, } \\
3 \text { years } \\
\text { prity }
\end{array}\right]+3\left[\begin{array}{c}
\text { annual consumption less production } \\
\text { (vice versa for plutonium) }
\end{array}\right.} \\
& \operatorname{CS}_{\mathrm{COAT}}^{\mathrm{t}} \\
& =\operatorname{CS}_{\mathrm{COAI}}^{\mathrm{t}-3} \\
& +3\left[.030\left(\mathrm{PC}_{\mathrm{COAL}}^{\mathrm{t}}+\overline{\mathrm{RI}}_{\mathrm{COAL}}^{\mathrm{t}}\right)\right] \\
& \mathrm{CS}_{\mathrm{PETG}}^{\mathrm{t}}=\mathrm{CS}_{\mathrm{PETG}}^{\mathrm{t}-3}+3\left[.030\left(\mathrm{PC}_{\mathrm{PETG}}^{\mathrm{t}}+\overline{\mathrm{RI}}_{\mathrm{PETG}}^{\mathrm{t}}\right)\right] \\
& +.50 n_{L}\left(D P_{L W R}^{t+3}-D P_{L W R}^{t-30}\right) \\
& \left.+.54 n_{H}\left(D P_{H T R B}^{t+3}-D P_{H T R B}^{t-30}\right)\right] \\
& \left.+2.0 n_{B}\left(D P_{F B R}^{t-30}-D P_{F B R}^{t}\right)\right]
\end{aligned}
$$

For the numerical For the reactor data, see Table note $b, p . B-4$ values of the thermal efficiency factors $n_{i}$, below. In each case, these factors denote the ratio of the electricity or hydrogen output to the primary energy input.

The exogenous terms $\overline{\mathrm{RI}}_{\mathbf{j}}^{t}$ refer to the remaining initial fossil fuel capacities ( $j=$ COAI, PETG).

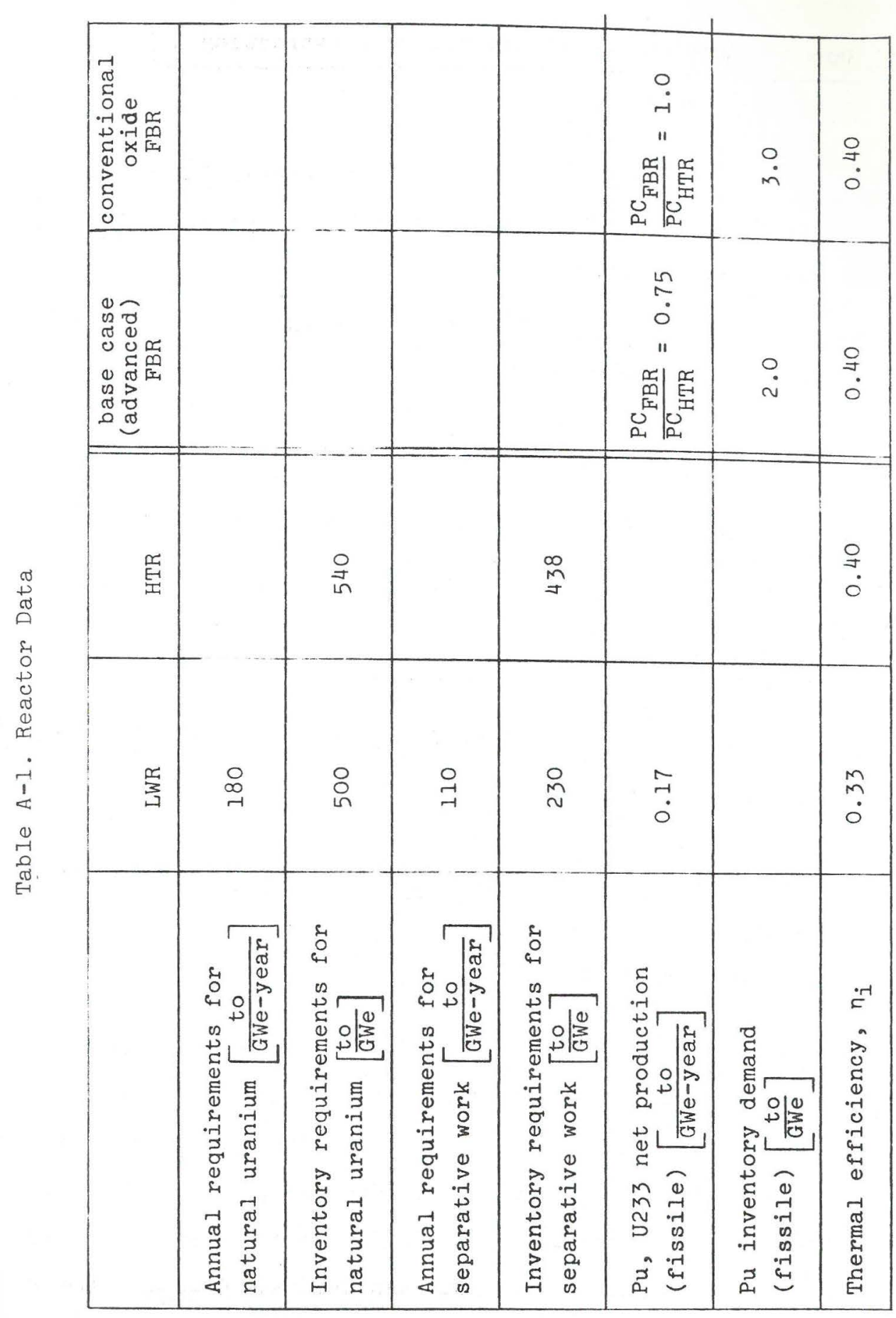


Upper bounds on cumulative resource extraction $\mathrm{CS}_{i}^{t}$

i $=$ PETG, NULC )

Upper bounds are placed upon the cumulative extraction of petroleum and of low-cost uranium ( $\$ 15 /$ pound). These con-

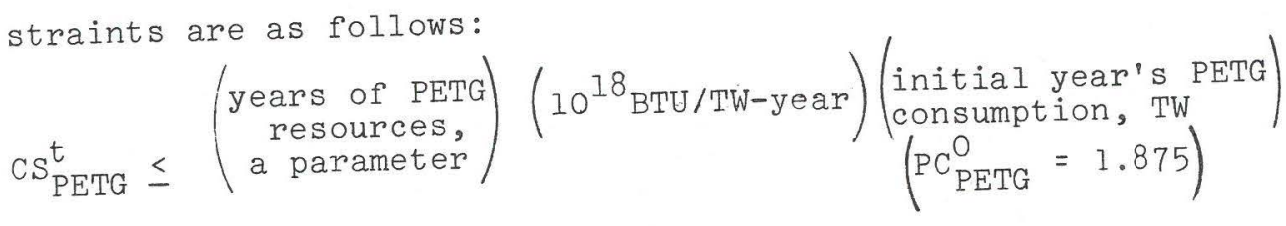

$C S_{\text {NULC }}^{t} \leq 2.0 \quad 10^{6}$ metric tons.

No upper bounds are imposed upon the unknowns $P C_{\mathrm{NUHC}}^{\mathrm{t}}$,

the extraction of high-cost natural uranium ( $\$ 50 /$ pound).

$D I_{j}^{t}$ - demands for intermediate items $(j=S W U, B R G N)$

$$
\mathrm{PC}_{\mathrm{SWU}}^{\mathrm{t}} \geq \operatorname{lin}_{\mathrm{L}} \mathrm{PC}_{\mathrm{LWR}}^{\mathrm{t}}+230 n_{\mathrm{L}}\left(\mathrm{DP} \mathrm{LWR}_{\mathrm{LWR}}^{\mathrm{t}+3}-\mathrm{DP}_{\mathrm{LWR}}^{\mathrm{t}-30}\right)
$$

(unit: $10^{6}$ tons/year)

$$
+.438 n_{\mathrm{H}}\left(D P_{\mathrm{HTRB}}^{t+3}-D P_{\mathrm{HTRB}}^{t-30}\right)
$$

$$
\mathrm{PC}_{\mathrm{FBR}}^{\mathrm{t}-3} \geq \quad \geq 75 \mathrm{PC}_{\mathrm{HTRB}}^{\mathrm{t}}+\mathrm{PC}_{\mathrm{FBPL}}^{\mathrm{t}}
$$

(unit: reactor

coupling factor)

This latter restriction refers to the use of the breeding gain in the FBR. The breeder may be employed to convert thorium into U233 fuel for the HTRB. Alternatively, it may be employed to produce plutonium. In the latter case, we assume an $8 \% /$ year gain (9-year system doubling time). Recall the coefficient for the unknown $\mathrm{PC}_{\mathrm{FBPL}}^{\mathrm{t}}$ in the equation defining $\mathrm{CS}_{\mathrm{PLUT}}^{\mathrm{t}}$. Its value depends, among other factors, upon the system's annual growth rate, .08 .

\section{$\mathrm{DM}_{j}^{\mathrm{t}}-$ final demands $(j=$ ELEC, NELE)}

In model societies 1 and 2, the final demands for energy are taken to be exogenous. In model society 3 , these demands are endogenous for they depend upon the costs of supply.

Electricity demands are stated in terms of equivalent $T W_{t h}$ for LWR efficiency $n_{L}=1 / 3$. This same efficiency factor holds for the remaining initial coal-fired electric plants. Hence :

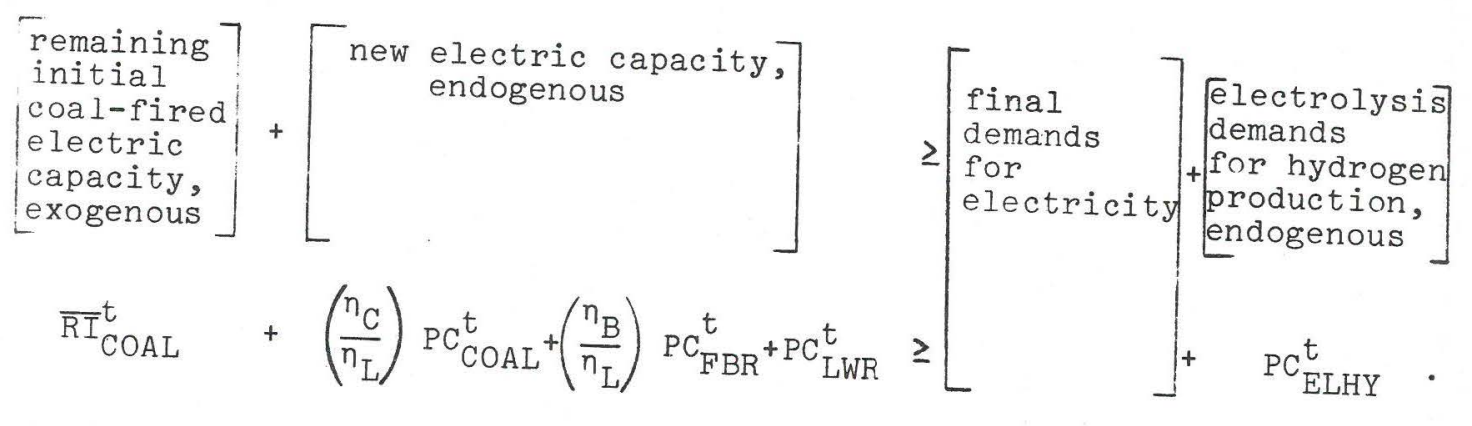

(unit: $\mathrm{TW}_{t h}$, LWR equivalent)

The remaining initial coal-fired capacity, $\overline{\mathrm{RI}}_{\mathrm{COAL}}^{\mathrm{t}}$, is calculated so that: 1) at time 0 , it is equal to the fina demand of $.625 \mathrm{TW}_{\mathrm{th}}$; 2) there is a 30-year service life; and 3) the capacity increments grew at the annual $8 \%$ during the 30 years preceding time 0 . Similar assumptions are employed to estimate the remaining initial petroleum and gas capacity $\overline{\mathrm{RI}}_{\mathrm{PETG}}^{\mathrm{t}}$, except that here the final demand is $1.875 \mathrm{TW}_{\text {th }}$ at time 0 , and it is supposed that the capacity increments grew at the annual rate of $4 \%$ prior to time 0. The rates of 8 and $4 \%$ are, respectively, identical to the final demand growth rates between years 0 and 3 for model society 1 . 
The non-electrical energy demands are stated in terms f equivalent TW for petroleum and gas. Each BTU of hydrogen will replace 2 BTU of petroleum and gas in ammonia manufacture, oil refining, petrochemicals, and air transport. (According to AET-8, Associated Universities [1], these (According to Ail use $25 \%$ of the natural gas and oil consumed in the U.S. in the year 2000.) Here, to be more conservative on the long-term prospects for substituting hydrogen, we have taken the hydrogen utlization factor $n_{U}=1.5$. Hence:

\begin{tabular}{|c|c|c|c|}
\hline $\begin{array}{l}\text { energy avail- } \\
\text { able from ini- } \\
\text { tial remaining } \\
\text { petroleum and } \\
\text { natural gas, } \\
\text { exogenous }\end{array}$ & $+\left[\begin{array}{l}\text { energy avail- } \\
\text { able from } \\
\text { petroleum and } \\
\text { natural gas, } \\
\text { endogenous }\end{array}+\right.$ & $\begin{array}{l}\text { BTU of pet- } \\
\text { roleum or } \\
\text { natural gas } \\
\text { replaced } \\
\text { per BTU of } \\
\text { hydrogen } \\
\text { utilized }\end{array}$ & $\begin{array}{l}\text { energy available from } \\
\text { hydrogen produced } \\
\text { through thermochemical } \\
\text { and electrolytic water- } \\
\text { splitting, endogenous }\end{array}$ \\
\hline$\overline{\mathrm{RI}}_{\mathrm{PETG}}^{\mathrm{t}}$ & $+\quad \mathrm{PC}_{\mathrm{PETG}}^{t}$ & $+\left\lceil n_{U}=1.5\right.$ & $n_{T} P C_{H T R B}^{t}+n_{L} n_{E} P C_{E L H Y}^{t}$ \\
\hline
\end{tabular}

Note that the primary energy input into electrolysis $\left(P_{C}^{t}\right)$ is multiplied both by the LWR and by the electrolyzer ELHY efficiency factors, even if it turns out that the FBR is the source of the electricity used. Recall that we have adopted the convention of The FBR ing electrical energy in terms of LWR equivalence. The FR efficiency factor demand equations.

\begin{tabular}{|c|c|c|}
\hline $\begin{array}{l}\text { plant } \\
\text { type } i\end{array}$ & & $\begin{array}{l}\operatorname{cur}_{i} \\
\left(\$ 10^{9} / \mathrm{yr}\right)\end{array}$ \\
\hline COAL & $\left(\$ 1 / 10^{6} \mathrm{BTU}\right)\left(3010^{15} \mathrm{BTU} / \mathrm{TW}-\mathrm{yr}\right)$ & 30.0 \\
\hline PETG & $\left(\$ 1.667 / 10^{6} \mathrm{BTU}\right)$ (30 $\left.10^{15} \mathrm{BTU} / \mathrm{TW}-\mathrm{yr}\right)$; equivalent to $\$ 10 / \mathrm{barre}$ & 50.0 \\
\hline SWU & $\left(\frac{\$ 20}{\mathrm{~kg}}\right)\left(\frac{10^{3} \mathrm{~kg}}{\operatorname{ton}}\right)\left(\frac{10^{6}}{10^{6}}\right)$ & 20 \\
\hline LWR & 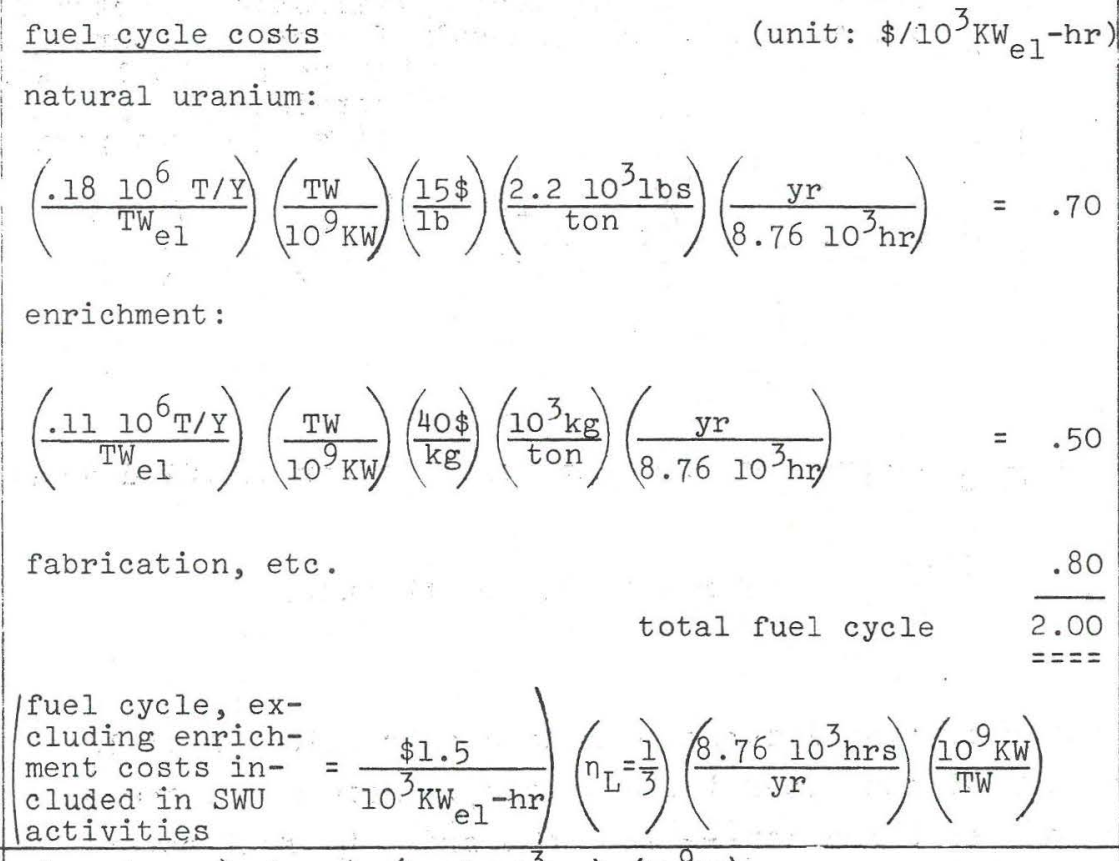 & 4.4 \\
\hline FBR & $\left(\frac{\$ 1}{10^{3} \mathrm{KW}_{\mathrm{el}}-\mathrm{hr}}\right)\left(\mathrm{n}_{\mathrm{B}}=.4\right)\left(\frac{8.7610^{3} \mathrm{hrs}}{\mathrm{yr}}\right)\left(\frac{10^{9} \mathrm{KW}}{\mathrm{TW}}\right)$ & 3.5 \\
\hline $\begin{array}{l}\text { HTRB, } \\
\text { HTRU }\end{array}$ & $\left(\frac{\$ 2}{10^{3} \mathrm{KW}_{\mathrm{eI}}-\mathrm{hr}}\right)\left(\mathrm{n}_{\mathrm{H}}=.4\right)\left(\frac{8.7610^{3} \mathrm{hrs}}{\mathrm{yr}}\right)\left(\frac{10^{9} \mathrm{KW}}{\mathrm{TW}}\right)$ & 7.0 \\
\hline NUHC & $\begin{array}{l}\text { natural uranium, high cost--for quantities in } \\
\text { addition to those available at } \$ 15 / 1 b \text { : } \\
(\$ 50-15 / 1 b)\left(\frac{2.210^{3} 1 b s}{\text { ton }}\right)\left(\frac{10^{6}}{10^{6}}\right)\end{array}$ & 77.0 \\
\hline
\end{tabular}


COST - minimand

Present value of costs incurred annually during each

3-year period over 75-year horizon:

$$
\begin{aligned}
& \left.\begin{array}{l}
\text { present } \\
\text { value }
\end{array}\right]\left[\begin{array}{l}
\text { current } \\
\text { cunvestment }
\end{array}\right)+\begin{array}{l}
\text { terminal } \\
\text { valuation } \\
\text { factor }
\end{array} \text { (present value } \text { factor for in- } \\
& \text { of 3-year costs, annual costs, annual factor, |curring capi- } \\
& \text { costs }
\end{aligned}
$$

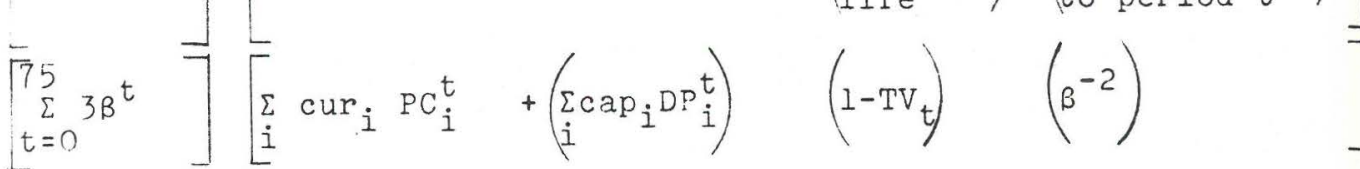

$$
\begin{aligned}
& t=0 \quad \text { L }
\end{aligned}
$$

\begin{tabular}{|c|c|c|}
\hline $\begin{array}{l}\text { plant } \\
\text { type } i\end{array}$ & & $\left.\begin{array}{r}c^{c a p} \\
\left(\$ 10^{9}\right.\end{array}\right)$ \\
\hline COAL & $\left(\frac{\$ 400}{\mathrm{KW}}\right)\left(\frac{1}{\mathrm{~L} \cdot \mathrm{F} \cdot}=1.2\right)\left(\mathrm{n}_{\mathrm{C}}=.4\right)\left(\frac{10^{9} \mathrm{KW}}{\mathrm{TW}}\right)$ & $\frac{192}{T w_{t h}}$ \\
\hline SWU & $\left(\frac{\$ 200}{\mathrm{~kg} / \mathrm{yr}}\right) \quad\left(\frac{10^{3} \mathrm{~kg}}{\text { ton }}\right)$ & $\frac{200}{10^{6} \text { tons /year }}$ \\
\hline LWR & $\left(\frac{\$ 500}{\mathrm{KW}}\right)\left(\frac{1}{\mathrm{~L} \cdot \mathrm{F} \cdot}=1.2\right) \quad\left(n_{\mathrm{L}}=\frac{1}{3}\right)\left(\frac{10^{9} \mathrm{KW}}{\mathrm{TW}}\right)$ & $\frac{200}{\mathrm{TW} W_{\text {th }}}$ \\
\hline FBR & $\left(\frac{\$ 550}{K W_{\mathrm{el}}}\right) \quad\left(\frac{1}{\mathrm{~L}_{\mathrm{F}} \mathrm{F}_{0}}=1.2\right) \quad\left(n_{\mathrm{B}}=.4\right) \quad\left(\frac{10^{9} \mathrm{KW}}{\mathrm{TW}}\right)$ & $\frac{264}{T W_{t h}}$ \\
\hline $\begin{array}{l}\text { HTRB, } \\
\text { HTRU }\end{array}$ & $\begin{array}{l}\left(\frac{\$ 500}{\mathrm{KW}}\right)\left(\frac{1}{\mathrm{~L} \cdot \mathrm{F} \cdot}=1.1\right) \quad\left(\eta_{\mathrm{H}}=.4\right) \quad\left(\frac{10^{9} \mathrm{KW}}{\mathrm{TW}}\right) \\
\mathrm{N.B} \text {. This includes both the nuclear plant } \\
\text { for process heat plus the thermochemical } \\
\text { plant for water-splitting. The chemical } \\
\text { plant is taken at the same investment cost } \\
\text { as the electricity generating side of an } \\
\text { HTGR installation. }\end{array}$ & $\frac{220}{T W_{t h}}$ \\
\hline ELHY & $\left(\frac{\$ 60}{\mathrm{KW}_{\mathrm{el}}}\right) \quad\left(n_{\mathrm{L}}=\frac{1}{3}\right) \quad\left(\frac{10^{9} \mathrm{KW}}{\mathrm{TW}}\right)$ & $\frac{20}{T^{T} W_{t h}}$ \\
\hline
\end{tabular}

It is supposed that interes, during construction is included in the capital cost coefficients, cap $p_{i}$. These costs are incurred at the commissioning date--two years prior to full power operations--hence the term $\beta^{-2}$.
Derivation of capital investment cost coefficients 
Static comparison of annual costs per $\mathrm{TW}_{\mathrm{th}}$

(neglecting costs and credits for plutonium and U233)

\begin{tabular}{|c|c|c|c|c|c|}
\hline & $\begin{array}{l}\text { plant } \\
\text { type i }\end{array}$ & $\operatorname{cur}_{i}$ & $.13\left(\mathrm{cap}_{i}\right)^{(a)}$ & $\begin{array}{l}\text { factor for LWR } \\
\text { or PETG } \\
\text { equivalence }\end{array}$ & $\begin{array}{l}\text { total annual costs } \\
\left(\$ 10^{9} / \mathrm{yr} \text { per } \mathrm{TW}_{\mathrm{th}}\right) \\
\text { expressed in LWR } \\
\text { or petroleum } \\
\text { equivalents }\end{array}$ \\
\hline \multirow{3}{*}{ ELEC $<$} & COAL & 30. & 25. & $\frac{n_{L}}{n_{C}}=.833$ & 46. \\
\hline & LWR & $5.8-10.5^{(c)}$ & 26. & 1. & $\begin{array}{l}32 .-36 \\
\text { (depending on } \\
\text { uranium cost) }\end{array}$ \\
\hline & FBR & 3.5 & 34. & $\frac{n_{L}}{n_{B}}=.833$ & 31. \\
\hline \multirow{3}{*}{ NELE ? } & ELHY & $\begin{array}{c}31 . \\
\text { (based upon } \\
\text { FBR costs) }\end{array}$ & 2.6 & $\frac{1}{\frac{\left.1 n_{L}\right)\left(n_{E}\right)\left(n_{U}\right)}{2.5}}=$ & 84. \\
\hline & PETG & 50. & 0 & 1. & 50. \\
\hline & HTRB & 7. & 28. & $\frac{1}{\left(n_{T}\right)\left(n_{U}\right)}=1.333$ & 47. \\
\hline
\end{tabular}

Notes: (a) $.13 /$ year $=\left(\begin{array}{l}\text { Pactor for in- } \\ \text { curring capital } \\ \text { costs 2 years } \\ \text { prior to full } \\ \text { power date }\end{array}\right)\left(\begin{array}{l}\text { annual capital } \\ \text { recovery factor, } \\ 30 \text { year life, } \\ \text { 10\% discount } \\ \text { rate }\end{array}\right)$

$$
=(1.1)^{2} \quad(.106)
$$

(b) efficiency factors(useful output/primary energy input):

$n_{L}=1 / 3$

$n_{B}=n_{C}=n_{H}=.4$

$n_{E}=.8=$ electrolyzer efficiency $n_{T}=.5=\begin{aligned} & \text { thermal efficiency for HTR plus thermo- } \\ & \text { chemical plant for water-splitting }\end{aligned}$

$n_{U}=1.5$ BTU of petroleum or natural gas replaced
per BTU of hydrogen utilized for oil refining, petrochemical and air transport.

(c) $5.8=(2.00)\left(\frac{1}{3}\right)(8.76)$; for uranium at $\$ 15 / 1 \mathrm{~b}$

$10.5=(3.60)\left(\frac{1}{3}\right)(8.76)$; for uranium at $\left.\$ 50 / 1 b\right)$
Appendix C: Analytic Solutions

for an All-Nuclear System

From the programming submatrix (Table 4 ), it is possible to calculate what is possible for an all-nuclear energy system requiring no fossil fuels, no electrolysis and virtually no enriched uranium.* The only feasible activities are then those for which the index $i=F B R, H T R B$ and FBPL. To shorten the notation, we adopt the following definitions, each referring to year $t$ :

$x_{1}=P_{\mathrm{FBR}}^{t} ; x_{2}=\mathrm{PC}_{\mathrm{HTRB}}^{\mathrm{t}} ; \mathrm{x}_{3}=\mathrm{PC}_{\mathrm{FBPL}}^{\mathrm{t}}$

$\theta=$ electricity, fraction of total primary energy demand

$1-\theta=$ non-electric energy, fraction of total primary energy demand

$\mathrm{g}=\underset{\text { annual growth rate of electricity demand and }}{\text { supply }}$

$\therefore\left(\frac{1}{1+3 g}\right) x_{1} \approx P C_{F B R}^{t-3}$ $\left(\frac{g}{1+3 g}\right) x_{1} \approx D_{F B R}^{t}=\begin{aligned} & \text { annual increase in capacity, net of } \\ & \text { retirements at end of } 30 \text {-year service }\end{aligned}$

For this technology to satisfy the final demand constraints $\mathrm{DM}_{\mathrm{ELEC}}^{\mathrm{t}}$ and $\mathrm{DM}_{\mathrm{NELE}}^{\mathrm{t}}$, the following must hold**:

$$
1.2 x_{1} \quad=\theta
$$

$$
.75 x_{2}=1-\theta
$$
${ }^{*}$ Small amounts of enriched uranium would be needed to
start up new HTRB capacity. The lower the growth rate, the start up new HTRB capacity. The lower the

** In equations (1) and (2), the coefficients 1.2 and .75 relative to the LWR and PETG thermal efficiency of the FBR is $40 \%$ and that of since the is $33 \%$, it is possible to replace 1.2 GW therma the LWR of GW electrical. 
Suppose that the system is to use up the entire breeding gain and also the plutonium available in period $t$. Then from Table 4 (rows $\mathrm{DI}_{\mathrm{BRGN}}^{\mathrm{t}}$ and $\mathrm{SM}_{\mathrm{PLUT}}^{\mathrm{t}}$ ):

$$
\begin{aligned}
& \left(\frac{-1}{1+3 g}\right) x_{1}+.75 x_{2}+x_{3}=0 \\
& \left(\frac{-2.4 g}{1+3 g}\right) x_{1}+.192 x_{3}=0
\end{aligned}
$$

Now set $\theta=1$, and therefore $x_{2}=0$. (That is, employ the entire breeding gain for plutonium production rather than HTR fuel.) Combining equations (3) and (4), it turns out that $\mathrm{g}=8 \%$ per year. This is the maximum rate at which an all-electric system could grow given the breeding gain of the base case FBR. This performance could be obtained through carbide rather than oxide fuel. Alternatively, the FBR cociant might be gas or molten salt.

For $x_{2}>0$, some of the breeding gain will have to be allocated to provide HTR fuel. By combining equations (1) (4), it may then be shown that:

$$
\theta=\frac{1}{1+.833\left(\frac{1-g / .08}{1+3 g}\right)}
$$

From (5), it can be seen how the electricity fraction $\theta$ depends upon the growth rate. For example, with an $8 \%$ growth rate, $\theta=100 \%$. With a zero growth rate, the electricity fraction $\theta$ is at its minimum--55\% of the total primary energy demand.

This is considerably higher than the initial value $(\theta=25 \%)$ in each of our "model societies."

For an all-nuclear supply system to match the demand-mix more closely, some technologies must be introduced in addition to the coupling of the FBR and HTR. Our programming model therefore includes several alternative activities: HTRU (HTR's fueled by enriched uranium) and ELHY (electrolytic production of hydrogen). Both of these lead to higher costs than the HTRB technology, but they provide greater flexibility in satisfying the demand-mix.

These options - based upon existing reactor technology would be particularly important if the FBR were of the conventional oxide type with a low breeding gain. The performance factors postulated for the oxide FBR are shown in parentheses in Table 4. Accordingly, equations (3)-(5) are revised as follows:

$$
\begin{aligned}
& \left(\frac{-1}{1+3 g}\right) x_{1}+x_{2}+x_{3}=0 \\
& \left(\frac{-3.6 g}{1+3 g}\right) x_{1}+.144 x_{3}=0 \\
& \theta=\frac{1}{1+.625\left(\frac{1-g / .04}{1+3 g}\right)} .
\end{aligned}
$$

In Figure C-l, we plot $\theta$ as a function of $\mathrm{g}$, both for the base case and for the oxide FBR. The base case technology enables the maximum growth rate of the electricity system to be 8 rather than $4 \%$ per year. At the other extreme--with a zero growth rate and the entire breeding gain allocated to the HTRB activity--it permits the electricity fraction $\theta$ to be reduced from 62 to $55 \%$. 


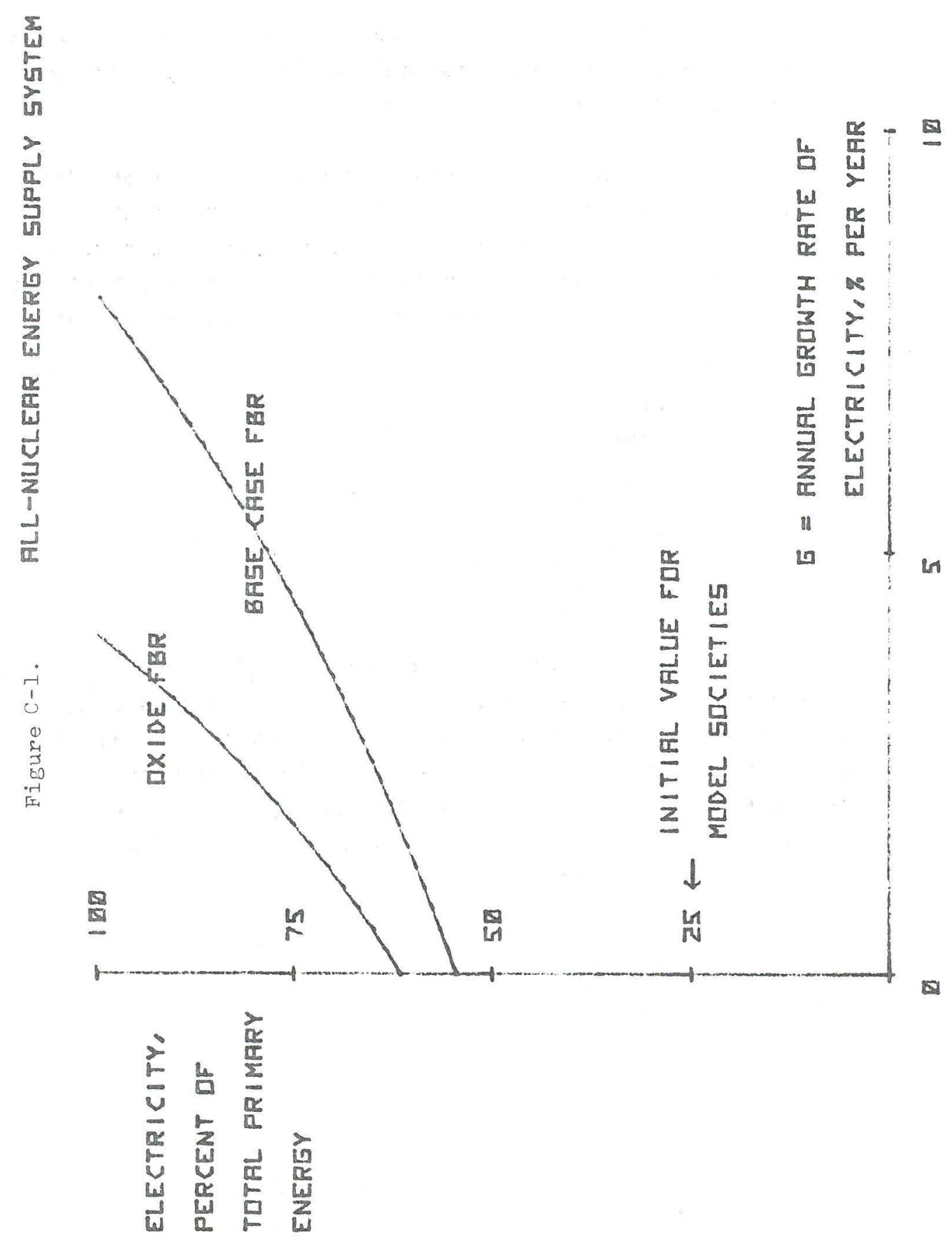


Figure D-la. NUCLEAR REACTDR CLNSTRUCTIIN RERUIREMENTS

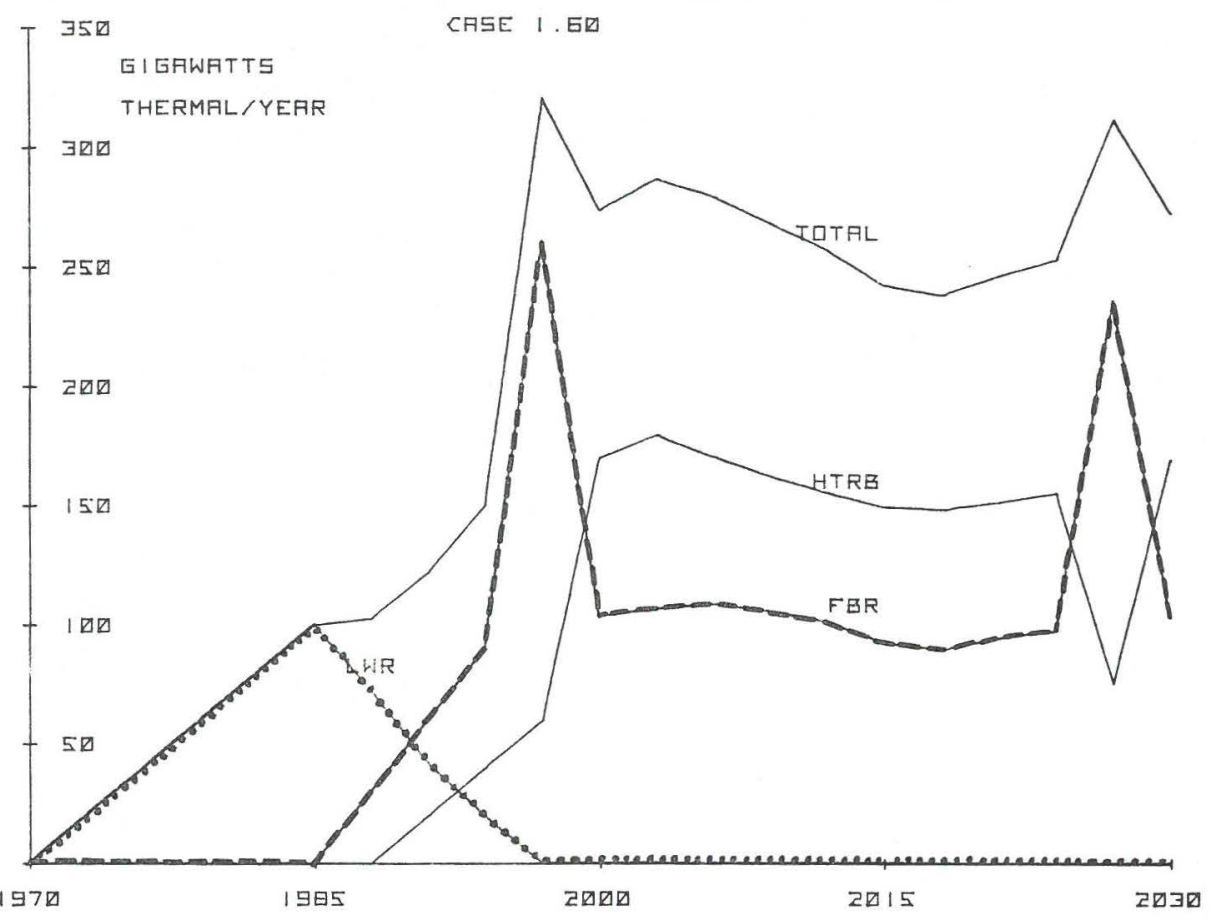

Figure D-Ib. NUCLEAR REACTIR CONSTRUCTIIN REQUIREMENTS

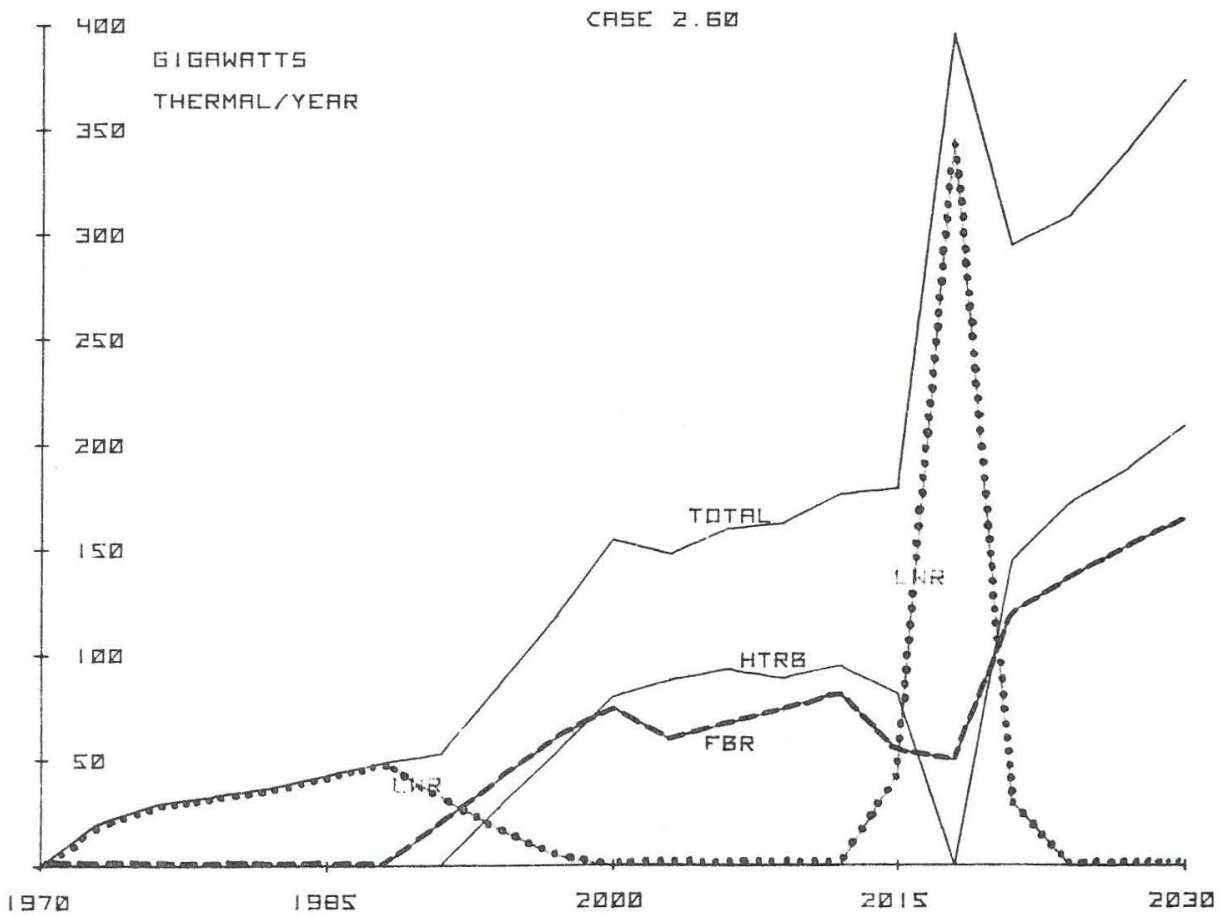



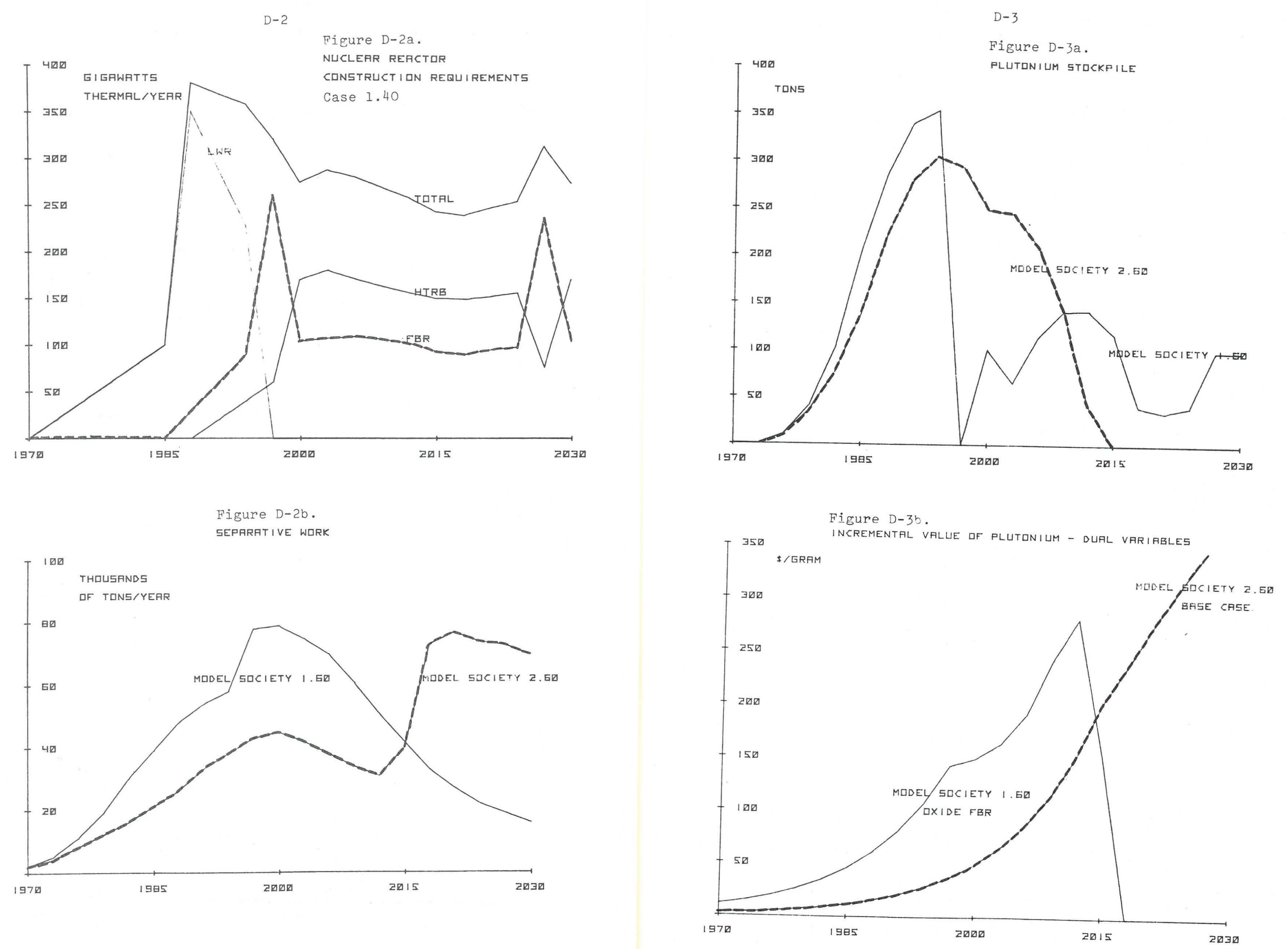
[1] Associated Universities, "Reference Energy Systems and Resource Data for Use in the Assessment of Energy Technologies," AET-8, Upton, New York, April 1972. [2] Atomic Energy Commission, Nuclear Power 1973-2000, WASH-1139(72)
UC-80, U.S. Government Printing Office, December 1972 .

[3] Bauerschmidt, R., H.Bossel, N.Chu, R.Denton, B.B. Hughes, H.-H. Maier, "Energy Models: Resources, Demand, Supply," M.Mesarovic and E.Pestel, directors, Technical University Hannover, March 1974.

[4] Doctor, R.D., et al., "California's Electricity Quandary: III, Slowing the Growth Rate," R-1116-NSF/CSA, RAND Corporation, Santa Monica, September 1973.

[5] Edmonson, N., "Real Price and the Consumption of Mineral Energy in the United States, 1901-1968," Journal of Industrial Economics, forthcoming, 1974 .

[6] Fortescue, P., "A Reactor Strategy: FBR's and HTGR's," Nuclear News, vol.15, no.4, April 1972.

[7] Häfele, W., "Hypotheticality, the New Challenges and the Pathfinder Role of Nuclear Energy," Minerva, July 1974 a.

[8] Hăfele, W., "Energy Systems," Bulletin International Atomic

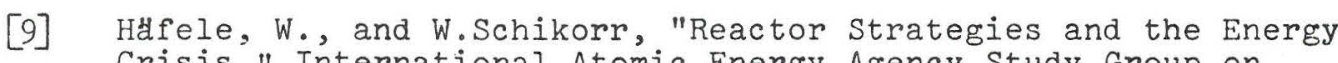
Crisis," International Atomic Energy Agency Study Group on Reactor Strategy Calculations, Vienna, (proceedings in press), November 1973.

[10] Manne, A.S., "Waiting for the Breeder," Review of Economic Studies, forthcoming, 1974.

[1] Manne, A.S., and C.Marchetti, "Hydrogen: Mechanisms and Strategies of Market Penetration," Hydrogen Economy Miami Energy Conference, March 1974.

[12] Marchetti, C., "Hydrogen and Energy," Chemical Economy and Engineering Review, Tokyo, January 1973.

[13] McKelvey, V.E., and D.C.Duncan, United States and World Resources of Energy, Mineral Resource Development Series, No.26, II, 1969 
References (continued)

[14] Samuelson, P.A., "Spatial Price Equilibrium and Linear

Programming," American Economic Review, vol.42, June 1952. [15] Sumner, D., and C.Johnson, "700,000,000,000 Barrels of Soot,"
Sierra Club Bulletin, April 1974.

[16] Theobald, P.K., S.P.Schweinfurth, and D.C.Duncan, Energy

Resources of the United States, Geological Survey Circular 650,

U.S.Department of the Interior, 1972 . 